\title{
The Audit of Deferred Taxes as a Signal for Tax Auditors: Tax Compliance Implications for Private and Public Firms*
}

March 29, 2017

Kay Blaufus, Jens Robert Schöndube and Stefan Wielenberg ${ }^{\dagger}$

\footnotetext{
${ }^{*}$ We thank Joachim Gassen, Laszlo Goerke, Kyungha Lee, Ulf Schiller, Alfred Wagenhofer, participants of the ARFA - Workshop 2015, the GEABA - Symposium 2015, the EAA - Conference 2016, the VHB - Conference 2016, and the EISAM Workshop on Accounting and Economics 2016 for helpful comments.

${ }^{\dagger}$ Department of Economics and Management Science, Leibniz Universität Hannover. Address: Königsworther Platz, 30167 Hannover, Germany.
} 


\title{
The Audit of Deferred Taxes as a Signal for Tax Auditors: Tax Compliance Implications for Private and Public Firms
}

\begin{abstract}
Using a tax compliance game, we study whether the observability of the taxpayer's financial accounting information and the statutory auditor's report affects the tax compliance. We find that firms' responses differ significantly between private and public firms. Private firms compensate for the reported signals by understating both book and tax valuations. We find that introducing the informative signals does not necessarily increase efficiency. In fact, for private firms, it may also lead to lower tax revenues. For public firms, however, the positive effect of using the informative signals on tax compliance is much more pronounced. The usage of audit reports in addition to financial accounting statements always increases tax revenues from public firms. Regarding changes in book-tax conformity, we find that higher book-tax conformity can lead to higher tax revenues from public firms; however, tax revenues from private firms decrease with higher book-tax conformity.
\end{abstract}

Keywords: Tax compliance game; Tax audit; Book-tax conformity; Strategic auditing.

JEL Classifications: H26, M41, M42. 


\section{Introduction}

Using a game-theoretical model, this paper investigates whether tax auditors should use additional information from financial accounting statements and statutory auditor reports to select their audit cases. In many countries, tax administration budgets declined significantly in recent years, and tax administrations, therefore, reduced their workforce. For example, the United States Internal Revenue Service reduced the number of its employees from 94,600 in 2010 to 78,100 in 2015 (Center on Budget and Policy Priorities 2016). Similarly, the number of employees at the U.K. tax authority, the HMRC, fell from 91,167 in 2005 to 61,370 in 2014 (Slemrod 2016). This raises the importance of improving the audit selection process to increase audit efficiency. The idea is straightforward: First, in general, values from financial accounting are positively correlated with values in tax accounting, meaning that financial accounting information could provide an informative signal for tax auditors (Mills and Sansing 2000). Second, financial accounting statements are often subject to a statutory audit that is conducted by an independent private auditor, usually a certified public accountant. The statutory audit includes the audit of deferred taxes that arise whenever there are temporary accounting differences between financial and tax accounting. If the statutory auditor confirms or doubts the deferred tax position in her audit report, this report provides an informative signal to the tax auditor with respect to the correct tax treatment. By using the information from financial accounting statements and the statutory auditor's report, tax auditors could thus improve their audit efficiency, which should in turn result in higher tax compliance. In line with this idea, firms in many countries are obliged to file their financial accounting statements together with their tax returns, e.g., in Australia, Canada, and the United Kingdom, and in some countries, firms must also file their audit report to the tax administration, e.g., in Belgium, Germany, and the United Kingdom (see Table 3, Appendix 6.1).

However, despite its potential to increase tax compliance, the usage of information 
from financial accounting statements and audit reports might also trigger opposing effects. Some firms may attempt to decrease detection risk and manipulate or avoid the signal, for example, by understating not only taxable income but also financial accounting income such that no deferred taxes arise. Other firms may have a further increased incentive to misreport taxable income. They could align financial and tax income by downward managing their taxable income and might thus benefít from lower audit probabilities for conforming reports. In contrast to intuition, the overall effect of using financial accounting information and audit reports in the tax audit selection process is therefore unclear. The aim of the current paper is to formally derive the conditions under which the usage of such additional information increases or decreases the efficiency in a strategic tax compliance game.

Most previous tax compliance research explains tax evasion as taxpayers maximizing their expected utility given the detection probability and the size of the penalty (Allingham and Sandmo 1972). However, this fails to recognize that the detection probability is in fact endogenous and the result of a game between taxpayers and the government. Graetz et al. (1986) and Reinganum and Wilde (1986) were the first to study tax compliance as a game in which the revenue agency could not credibly commit to an audit strategy. Reinganum and Wilde (1988) introduce taxpayer uncertainty regarding the government's audit costs, and Beck and Jung (1989) consider tax liability uncertainty. In Beck et al. (1996), taxpayers are allowed to purchase tax advice to resolve all uncertainty. Erard and Feinstein (1994) modify the approach of Reinganum and Wilde (1986) to consider nonstrategic taxpayers. Rhoades (1999) analyzes the impact of component reporting on the tax compliance game. Bayer (2006) considers taxpayers' concealment costs and demonstrates that higher tax rates lead to higher tax evasion and higher concealment and audit costs. Other studies analyze the effect of a signal regarding the taxpayer's income on the audit process. Sansing (1993) examines a signal regarding the correct tax treatment of a loss. He demonstrates that this signal can result in an increased amount of tax evasion while tax revenues (before audit 
costs) remain unaffected. Beck et al. (2000) study the effect of voluntary disclosures regarding an uncertain tax benefit to avoid a substantial underpayment penalty if the tax return is audited. Related to the study of Beck et al. (2000), De Simone et al. (2013) investigate the benefits of "Enhanced Relationship Tax Compliance Programs".

The two studies most related to our paper are Mills and Sansing (2000) and Mills et al. (2010). In Mills and Sansing (2000), the tax auditor observes the (correct) financial statement valuation, which results in a higher audit probability for positive book-tax-differences. Mills et al. (2010) investigate the effects of disclosed uncertain tax positions according to FIN 48. Contradicting public opinion, they demonstrate that some taxpayers will actually benefit from the mandatory disclosure requirements. We contribute to this research by studying the effect of a (imperfect) statutory audit of deferred taxes. By contrast, previous studies assume that independent auditors ensure consistently correct financial reporting. Moreover, previous research treats the financial accounting report as exogenous. We expand these models by allowing taxpayers to misreport both financial and tax reporting positions. Importantly, firms differ in their willingness to understate their financial accounting income to save on taxes. We follow an extensive literature demonstrating that private firms place less emphasis on financial reporting outcomes than do publicly listed firms (Mills 1998, Mills and Newberry 2001, Beuselinck et al. 2015, Lynch et al. 2017). Thus, in our analysis, we differentiate between public and private firms, where only the latter are willing to understate financial accounting income to save on taxes.

Our analysis proceeds in three steps. In a benchmark case, we assume that no observable information beyond the reported tax return is available. A firm's taxable income can be either low or high; similarly, a firm's financial accounting income can be either low or high. Firms decide whether to report their taxable income truthfully or whether to evade taxes. Tax auditors decide, based on the reported tax returns, whether to conduct a tax audit. In a second step, we add observable financial accounting information, and financial accounting values are positively correlated with tax values. Firms can 
now decide not only on reports for tax purposes but also for financial accounting purposes. In a third step, we integrate an observable statutory auditor report that includes a noisy signal on the correctness of deferred taxes.

Our findings reveal that the firm's responses to the tax auditor's usage of information from financial accounting and audit reports differ significantly between private and public firms. The average tax evasion of private firms is not affected by the observability of financial accounting information because private firms compensate for the informative financial statement signal by understating both financial accounting and tax valuations. Only if the audit report is also observable does tax evasion by private firms decrease. In contrast, tax evasion by public firms is much more responsive to the informative signals because public firms cannot avoid the signaling by underreporting financial accounting income due to their strict preference for high financial accounting values.

Furthermore the tax revenue implications differ between public and private firms. Surprisingly, for private firms, the observability of an audit report may lead to lower tax revenues. This result depends on the incentives of the tax auditor and the book-tax conformity. Only if we assume high-powered tax auditor incentives does the signal increase tax revenues from private firms and reduce audit costs. With low-powered tax auditor incentives, private firms have an incentive to present conforming tax and financial statements to avoid the signal. This can result in lower tax revenues, in particular, if book-tax-conformity is high. In contrast, for public firms, the observability of the audit report always increases tax revenues compared to the situation with only observable financial accounting statements. However, if we compare tax revenues with those in the setting without information, we observe that tax revenues could also decrease due to the informative signals. This holds for both public and private firms.

Overall, tax revenue and audit cost implications are highly complex and largely depend on tax auditor incentives, book-tax conformity, the firms' preference for tax savings, the firms' financial reporting costs, and the tax competence of the statutory auditor. 
One main finding is that higher book-tax conformity decreases tax revenues from private firms, whereas it increases tax revenues from public firms if tax auditors are not highly incentivized. Previous empirical studies on the effect of book-tax-conformity on tax avoidance use only data from publicly listed firms. These studies find a positive effect of book-tax conformity on tax compliance (Chan et al. 2010, Atwood et al. 2012, Tang 2015). This is in line with our results for public firms if tax auditors are not highly incentivized. However, in light of our results, one should be cautious in generalizing our empirical findings to private firms because we would expect exactly the opposite effect of book-tax conformity for private firms. Moreover, for private firms, higher book-tax conformity leads to less-informative financial statements, as firms understate their assets in their financial statements to reduce expected tax payments.

The remainder of this paper is organized as follows: In the second section, we present the model. In the third section, we conduct the equilibrium analysis. We begin by analyzing the equilibrium effect of observable financial statement valuation (section 3.1) and then integrate the observable audit report (section 3.2). Section 4 investigates the efficiency implications of the equilibrium, and the last section concludes the paper.

\section{The model}

We consider a sequential game to analyze the interactions between tax and financial statement valuation, the audit of financial statements, and tax audits. In the first stage the manager of a firm (in the following denoted as taxpayer) faces an asset valuation issue. The asset's correct book value in the financial statements is $b \in\{\underline{b}, \bar{b}\}$. The same valuation issue arises for tax purposes, where the proper valuation is $t \in\{\underline{t}, \bar{t}\}$. We define $\Delta_{b}=\bar{b}-\underline{b}$ and $\Delta_{t}=\bar{t}-\underline{t}$ and assume $\bar{b}=\bar{t}$ and $\underline{b}=\underline{t}$. Thus, $\Delta_{b}=\Delta_{t}=\Delta$. The correct valuations are the taxpayer's private information ${ }^{1}$ and we assume the following

\footnotetext{
${ }^{1}$ We do not adress taxpayer's uncertainty about the correct valuations in this paper. An analysis of tax uncertainty can be found in Graetz et al. (1986), Beck and Jung (1989), Beck et al. (1996), Mills et al. (2010), or Simone et al. (2013), for example.
} 
common prior probability distribution over the taxpayer's type:

Assumption 1 1. The ex ante probabilities $\operatorname{Prob}\{\underline{t}\}$ and $\operatorname{Prob}\{\bar{t}\}$ are 0.5.

2. The conditional probabilities $\operatorname{Prob}\{b \mid t\}$ are given by $\operatorname{Prob}\{\underline{b} \mid \underline{t}\}=\operatorname{Prob}\{\bar{b} \mid \bar{t}\}=p$ and $\operatorname{Prob}\{\bar{b} \mid \underline{t}\}=\operatorname{Prob}\{\underline{b} \mid \bar{t}\}=1-p$. We assume $0.5<p<1$.

The joint probabilities are $\operatorname{Prob}\{\bar{b}, \underline{t}\}=0.5(1-p), \operatorname{Prob}\{\bar{b}, \bar{t}\}=0.5 p, \operatorname{Prob}\{\underline{b}, \underline{t}\}=$ $0.5 p$ und $\operatorname{Prob}\{\underline{b}, \bar{t}\}=0.5(1-p)$. Furthermore, $\operatorname{Prob}\{\underline{b}\}=\operatorname{Prob}\{\bar{b}\}=0.5$.

Assumption 1 ensures that in the joint probability distribution for tax and financial statement valuation $t$ and $b$ are interchangeable. Furthermore, the parameter $p$ can be interpreted as a measure of the conformity between tax and financial statement valuation. A strong conformity will be given if $p \rightarrow 1$, and a low conformity is represented by $p \rightarrow 0.5$. In this sense, the assumption $p>0.5$ ensures that the correlation between tax law and financial statement valuation is positive.

After observing the proper values, the taxpayer decides about the valuations $\hat{b}$ and $\hat{t}$ to be reported. The taxpayer may bias the valuation because he is interested in low earnings for tax assessment and in high earnings in the financial statements. We assume that the taxpayer maximizes the objective function

$$
\max _{\hat{b}, \hat{t}} \mathbb{E}\left(\omega \cdot b^{\prime}-\gamma \cdot t^{\prime}-S\left(t^{\prime}\right)-H\left(b^{\prime}\right)\right)
$$

where $b^{\prime}=b^{\prime}(\hat{b}, \hat{t})$ and $t^{\prime}=t^{\prime}(\hat{b}, \hat{t})$ are the valuations after tax and financial statement audits given the reports $\hat{b}$ and $\hat{t}$. $S$ and $H$ denote disutility from monetary penalties and reputational losses due when an incorrect valuation is detected either in the tax or in the financial statements, respectively. They are defined by

$$
S\left(t^{\prime}\right)=\left\{\begin{array}{ll}
S, & \text { if } t^{\prime} \neq \hat{t} \\
0, & \text { else }
\end{array} \text { and } H\left(b^{\prime}\right)= \begin{cases}H, & \text { if } b^{\prime} \neq \hat{b} \\
0, & \text { else }\end{cases}\right.
$$


The parameters $\omega$ and $\gamma$ are positive weights indicating the taxpayer's preferences for financial statement and tax valuation. In the following, we consider two different types of taxpayer firms:

1. $\gamma>\omega$ indicates that the taxpayer's preferences are more sensitive to the tax than to the financial statement valuation. This is typical for firms characterized by almost no capital market exposure, by managers not driven by financial reporting measures and by less important outside debt financing. We denote taxpayers with $\gamma>\omega$ as private firms for the remainder of the paper.

2. $\gamma<\omega$ characterizes firms where tax reporting decisions are less important than financial reporting. For example, in big firms reporting is delegated to managers whose incentives are strongly affected by financial reporting measures if their remuneration is linked to them. Additionally, financial reporting may be important because capital market financing requires regular financial reports. In the following, we call firms with $\omega \geq \gamma$ publicly listed firms. Note that the above distinction between private and public firms follows an extensive research that shows private firms place less emphasis on financial reporting outcomes than publicly listed firms (Mills 1998, Mills and Newberry 2001, Beuselinck et al. 2015, Lynch et al. 2017).

In the next stage the statutory auditor conducts the annual financial statement audit. The auditor is not modeled as a strategic player and acts as follows:

1. The financial statements show deferred tax assets or liabilities whenever $\hat{b} \neq \hat{t}$. This position critically depends on the tax valuation $\hat{t}$, and, thus, the auditor reports on the validity of $\hat{t}$. This report is denoted as signal $\sigma$. The auditor may confirm $(\sigma=C)$ or doubt $(\sigma=D)$ the reported tax valuation. The statistical relation between the auditor's report on the tax valuation after observing $\hat{t}=\underline{t}$ and the true valuation is given by 


$$
\operatorname{Prob}\{\sigma \mid t, \hat{t}=\underline{t}\}=\begin{array}{c|cc} 
& \sigma=C & \sigma=D \\
\hline t=\underline{t} & \mu & 1-\mu \\
t=\bar{t} & 1-\lambda & \lambda
\end{array}
$$

Intuitively, the parameters $\mu, \lambda \in[0.5,1]$ denote the auditor's tax competence. $\mu=\lambda=1$ represents a fully competent auditor, and $\mu=\lambda=0.5$ an auditor with no competences in tax valuation.

It is not necessary to specify such a relation for $\hat{b}=\underline{b}$ and $\hat{t}=\bar{t}$, because the model assumptions (explained below) are such that the tax auditor never audits a high tax valuation. Therefore, the auditor's report $\sigma$ will never have any value to the tax auditor.

2. The statutory auditor always confirms a correct high valuation $\hat{b}=\bar{b}$ and accepts an overreported false report with probability $\xi_{h}$. An incorrect low valuation $\underline{b}$ will be accepted with a probability $\xi_{l}$ with $0 \leq \xi_{h}<\xi_{l}{ }^{2}$ For the sake of simplicity, we assume $\xi_{h}=0$ and $\xi_{l}=1$. We assume a sufficiently large penalty $H$, such that $\hat{b}=\bar{b}$ in case of a true valuation $\underline{b}$ is never optimal for the taxpayer.

The second strategic player is the risk neutral tax auditor, who observes the valuations $\hat{b}, \hat{t}$ and (if any) the auditor's report $\sigma=C$ or $\sigma=D$. The auditor may then decide to audit the tax valuation $(a=1)$ or not $(a=0)$. For the sake of simplicity, we assume a perfect tax audit technology. The tax auditor benefits from detecting an understated tax valuation (represented by the preference parameter $\delta$ ) and incurs personal audit costs $K_{S}$, if an audit is conducted. Thus, his objective function is

$$
\max _{a \in\{0,1\}} \mathbb{E}\left(\delta \max \left\{t^{\prime}(a)-\hat{t}, 0\right\}-K(a)\right),
$$

\footnotetext{
${ }^{2}$ Francis and Krishnan (1999) provide some evidence that auditors are more likely to issue modified audit reports for high income-increasing accruals than for high income decreasing accruals.
} 
where

$$
t^{\prime}(a)=\left\{\begin{array}{ll}
\hat{t}, & \text { if } a=0 \\
t, & \text { else }
\end{array} \text { and } K(a)= \begin{cases}K_{S}, & \text { if } a=1 \\
0, & \text { else }\end{cases}\right.
$$

In order to generate tax audit incentives we have to assume $\delta \Delta-K_{S}>0$. Obviously, the tax auditor will never review a tax valuation $\hat{t}=\bar{t}$. The following figure 1 summarizes the timing of our model. ${ }^{3}$

\section{Taxpayer's type Taxpayer reports Report on def. tax Tax auditor audits}

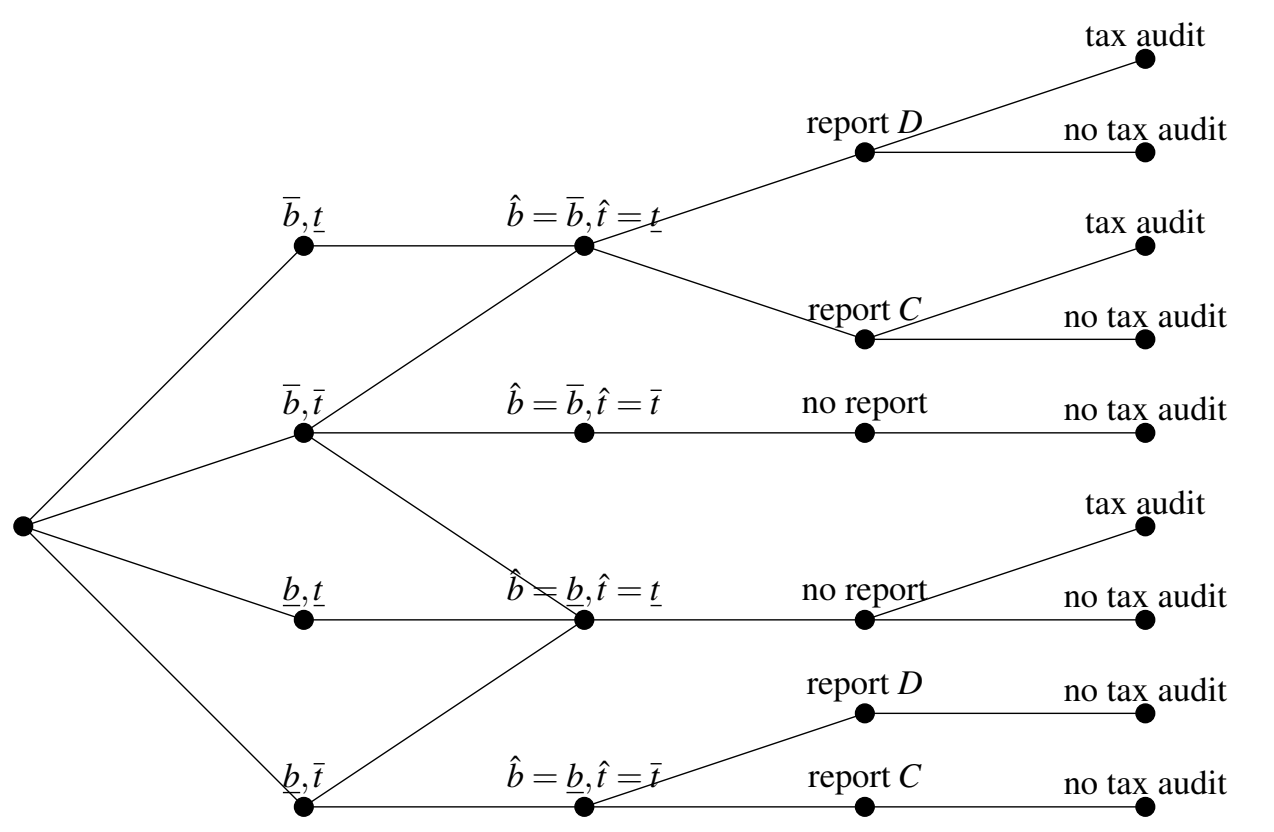

Figure 1: Timing and strategies in the model: First, nature assigns a type $b, t$ to the firm. Knowing his type, the taxpayer releases a report $(\hat{b}, \hat{t})$. If tax and financial statement valuations differ, the statutory auditor generates a signal $\sigma \in\{C, D\}$. At the last stage, the tax auditor decides on auditing the tax valuation (conditional $\sigma$, if available, and on $(\hat{b}, \hat{t})$ ).

\section{Equilibrium analysis}

In this section, we look at the taxpayer's and the tax auditor's equilibrium strategies. The key question analyzed here is how an auditor's opinion on deferred taxes influ-

\footnotetext{
${ }^{3}$ The figure is not an extensive form game tree. Information sets are not considered and we also supressed actions never played in equilibrium (as discussed above).
} 
ences taxpayer's reporting and the tax auditor's inspection behavior. Thus, we develop our equilibrium analysis in three stages. In the first step, financial statement valuation is unobservable by the tax auditor. In the second step, we show how the observable financial statement valuation is used in an equilibrium. In our third step, we derive the equilibrium with the auditor's report on deferred taxes available to the tax auditor.

\subsection{Unobservable and observable financial statement valuation}

As a first step, we compute the equilibrium without observable financial statement valuation and auditor's verification of deferred taxes. In this case, the game boils down to a simple variant of the inspection game. Thus, proposition 1 replicates the equilibrium strategies well known in the literature.

Proposition 1 Suppose that the tax auditor can observe neither the financial statement valuation nor the auditor's opinion with respect to deferred taxes. In this case, the equilibrium strategies are as follows:

- Taxpayer: Type $\underline{t}$ reports truthfully. Type $\bar{t}$ reports $\underline{t}$ with probability $\theta=\frac{K_{S}}{\delta \Delta-K_{S}}$ as long as $\frac{K_{S}}{\delta \Delta-K_{S}} \leq 1$. Type $\bar{t}$ always reports $\underline{t}$ for $\frac{K_{S}}{\delta \Delta-K_{S}}>1$.

- Tax auditor: Report $\bar{t}$ is never verified. Report $\underline{t}$ is verified with probability $\beta^{o}=\frac{\gamma \Delta}{\gamma \Delta+S}$ for $\frac{K_{S}}{\delta \Delta-K_{S}} \leq 1$ and never for $\frac{K_{S}}{\delta \Delta-K_{S}}>1$.

Proof: See appendix.

The term $\theta=\frac{K_{S}}{\delta \Delta-K_{S}}$ can be interpreted as a reverse measure of the tax auditor's incentives. Low values of $\theta$ represent low audit costs and high rewards for detecting underreporting, implying high powered incentives. A combination of high audit costs and low rewards yields low powered incentives to the tax auditor and a large $\theta$.

Proposition 1 states that the taxpayers's misreporting probability decreases with the tax auditor's net incentives. The unique mixed strategy equilibrium vanishes if net 
incentives become very low. In this case, the taxpayer always misreports and the tax auditor never challenges the reported tax valuation.

The equilibrium will generally not remain valid if the tax auditor can observe the taxpayer's financial statement valuation. Since $b$ can be informative about the true tax valuation $t$, the tax auditor will make use of this information. Proposition 2 states the concrete strategies:

Proposition 2 Suppose the tax auditor can observe the book value b. Then the equilibrium consists of the following strategies:

- Types $\bar{b}, \underline{t}$ and $\underline{b}, \underline{t}$ always report their true valuations.

- The tax auditor never audits a tax valuation $\bar{t}$.

In case of a private firm $(\omega<\gamma)$, the following probabilities are assigned to types' $\bar{b}, \bar{t}$ and $\underline{b}, \bar{t}$ reporting strategies and the tax auditor's audit strategies upon receiving reports $(\bar{b}, \underline{t})$ and $(\underline{b}, \underline{t})$ :

\begin{tabular}{l|lll}
\hline & $\theta \leq \frac{1-p}{p}$ & $\frac{1-p}{p}<\theta \leq 1$ & $1<\theta \leq \frac{p}{1-p}$ \\
\hline Type $\bar{b}, \bar{t}$ reports $(\bar{b}, \underline{t})$ & $\phi=\frac{1-p}{p} \theta$ & $\phi$ & $\phi$ \\
Type $\bar{b}, \bar{t}$ reports $(\underline{b}, \underline{t})$ & 0 & $v=\theta-\frac{1-p}{p}$ & $v=1-\phi$ \\
Type $\bar{b}, \bar{t}$ reports $(\bar{b}, \bar{t})$ & $1-\phi$ & $1-\phi-v$ & 0 \\
\hline Type $\underline{b}, \bar{t}$ reports $(\underline{b}, \underline{t})$ & $\eta=\frac{p}{1-p} \theta$ & 1 & 1 \\
Type $\underline{b}, \bar{t}$ reports $(\underline{b}, \bar{t})$ & $1-\eta$ & 0 & 0 \\
\hline Audit report $(\bar{b}, \underline{t})$ & $\alpha^{f}=\frac{\gamma \Delta}{\gamma \Delta+S}$ & $\alpha^{f}=\frac{\gamma \Delta}{\gamma \Delta+S}$ & $\alpha^{f}=\frac{\omega \Delta}{\gamma \Delta+S}$ \\
Audit report $(\underline{b}, \underline{t})$ & $\beta^{f}=\frac{\gamma \Delta}{\gamma \Delta+S}$ & $\beta^{f}=\frac{\Delta(\gamma-\omega)}{\gamma \Delta+S}$ & $\beta^{f}=0$ \\
\hline
\end{tabular}

In case of a publicly owned firm $(\omega \geq \gamma)$, the reporting and audit strategies are 


\begin{tabular}{l|ll}
\hline & $\theta \leq \frac{1-p}{p}$ & $\frac{1-p}{p}<\theta \leq \frac{p}{1-p}$ \\
\hline Type $\bar{b}, \bar{t}$ reports $(\bar{b}, \underline{t})$ & $\phi=\frac{1-p}{p} \theta$ & $\phi$ \\
Type $\bar{b}, \bar{t}$ reports $(\bar{b}, \bar{t})$ & $1-\phi$ & $1-\phi$ \\
\hline Type $\underline{b}, \bar{t}$ reports $(\underline{b}, \underline{t})$ & $\eta=\frac{p}{1-p} \theta$ & 1 \\
Type $\underline{b}, \bar{t}$ reports $(\underline{b}, \bar{t})$ & $1-\eta$ & 0 \\
\hline Audit report $(\bar{b}, \underline{t})$ & $\alpha^{f}=\frac{\gamma \Delta}{\gamma \Delta+S}$ & $\alpha^{f}=\frac{\gamma \Delta}{\gamma \Delta+S}$ \\
Audit report $(\underline{b}, \underline{t})$ & $\beta^{f}=\frac{\gamma \Delta}{\gamma \Delta+S}$ & $\beta^{f}=0$ \\
\hline
\end{tabular}

If $\theta>\frac{p}{1-p}$, both types $\bar{b}, \bar{t}$ and $\underline{b}, \bar{t}$ always report $\underline{t}$ and the tax auditor never audits.

Proof: See appendix.

Proposition 2 shows that the equilibrium strategies depend not only on the auditor's incentives (represented by $\theta$ ) but also on the conformity between commercial and tax law (represented by $p$ ). The term $\frac{1-p}{p}$ approaches zero in case of strong conformity $(p \rightarrow 1)$ and it approaches 1 , if financial statement and tax valuation are independent $(p \rightarrow 0.5)$. Moreover, compared to proposition 1 the range of nontrivial equilibria extends from $\theta \leq 1$ to $\theta \leq \frac{p}{1-p}$. This is due to the more sophisticated audit strategy facilitated by additional information.

The mixed strategy equilibrium is characterized by two generic properties: (1) Taxpayers will only report those combinations of $b$ and $t$ with a positive probability that lead to identical expected payoffs given the equilibrium tax audit probabilities. (2) The probabilities of reporting these alternatives make the tax auditor indifferent between auditing and not auditing the reports $(\underline{b}, \underline{t})$ and $(\bar{b}, \underline{t})$. This payoff equality in equilibrium is responsible for the main difference between the reporting strategies of taxpayers with both a high financial statement and tax valuation in private and publicly listed firms as will be explicated below.

The reporting strategies of type $\bar{t}$ taxpayers are depicted in figure 2. Under high powered auditor incentives $\left(\theta<\frac{(1-p)}{p}\right)$ the reporting behaviour does not depend on the 


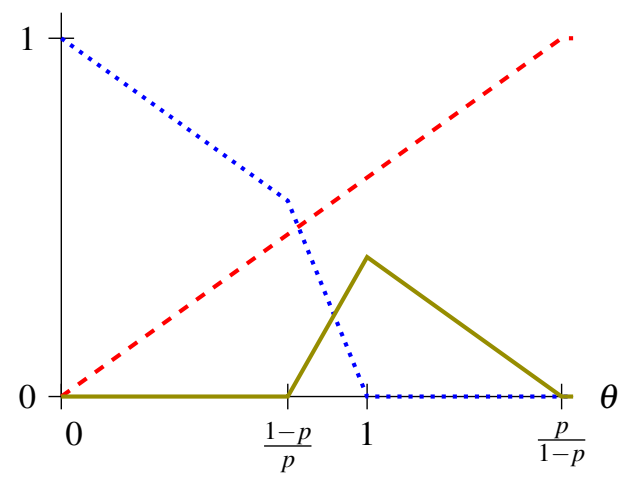

(a) Private firm $(\gamma>\omega)$

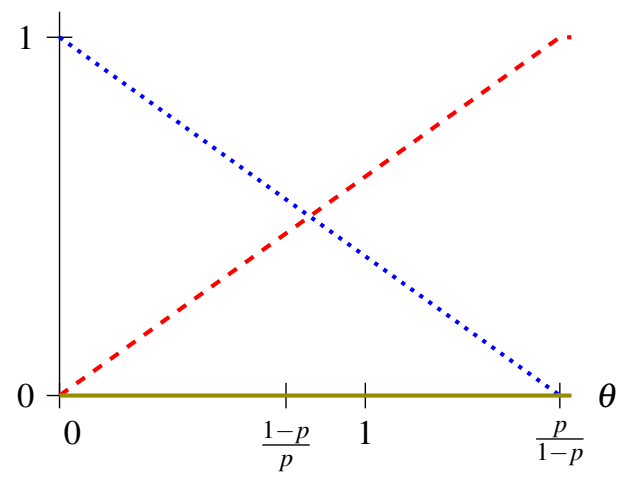

(b) Publicly owned firm $(\omega \geq \gamma)$

Figure 2: Type $\bar{b}, \bar{t}$ reporting strategies as a function of $\theta . \theta$ measures the tax auditor's incentives (as defined in Proposition 1). With increasing $\theta$ the tax auditor's incentives decrease. The dotted line depicts $\operatorname{Prob}\{(\hat{b}, \hat{t})=(\bar{b}, \bar{t})\}$, the dashed line $\operatorname{Prob}\{(\hat{b}, \hat{t})=(\bar{b}, t)\}$ and the solid line $\operatorname{Prob}\{(\hat{b}, \hat{t})=(\underline{b}, \underline{t})\}$.

relation between $\gamma$ and $\omega$. Type $\bar{b}, \bar{t}$ is indifferent between the truth and imitating type $\bar{b}, t$. This region gets especially small for high tax conformity $\left(\frac{(1-p)}{p} \rightarrow 0\right)$ because of the lower ex ante probability of type $\bar{b}, \underline{t}$.

Decreasing the tax auditor's incentives changes the reporting strategies in different ways. Together with a lower tax audit probability of report $(\underline{b}, \underline{t})$, type $\underline{b}, \bar{t}$ always underreports the tax valuation. Type $\bar{b}, \bar{t}$ taxpayers in private firms additionally understate book and tax valuation with positive probability. The latter is a reaction to the tax auditor's ability to exploit correlations between financial statement and tax valuation. In a public firm, however, understating the financial statement valuation is not attractive for type $\bar{b}, \bar{t}$, because $\omega>\gamma$ implies $\omega \bar{b}-\gamma \bar{t}>\omega \underline{b}-\gamma \underline{t}$. Thus, reporting $\underline{b}$ together with $\underline{t}$ cannot be part of an equilibrium.

In case of $1<\theta<\frac{p}{1-p}$, the tax auditor's incentives are such that the report $(\underline{b}, \underline{t})$ will never be verified. Then, a private firm taxpayer with type $\bar{b}, \bar{t}$ never reveals his true type but is indifferent between reporting $\underline{t}$ together with either $\underline{b}$ or $\bar{b}$. Taxpayers of type $\bar{b}, \bar{t}$ in publicly listed firms, however, are still indifferent between truthful reporting and report $(\bar{b}, \underline{t})$. 
Figure 3 shows the tax auditor's corresponding audit probabilities. We observe a pattern typical for mixed strategy equilibria: The tax auditor's incentives influence the taxpayer's strategies but not the audit probabilities $\beta^{f}$ and $\alpha^{f}$. They only change with a switch in the equilibrium regions.

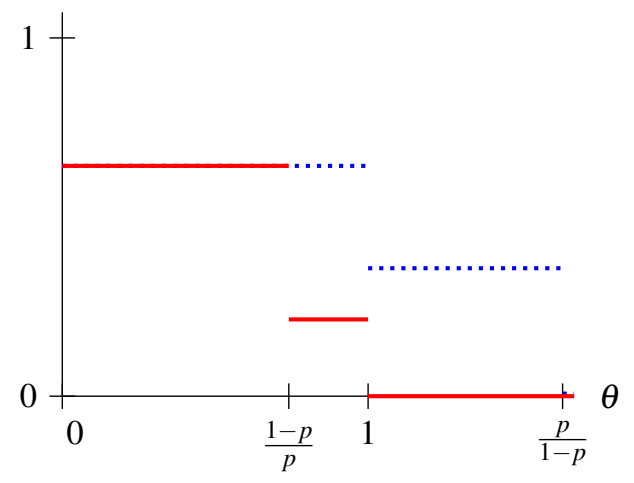

(a) Private firm $(\gamma>\omega)$

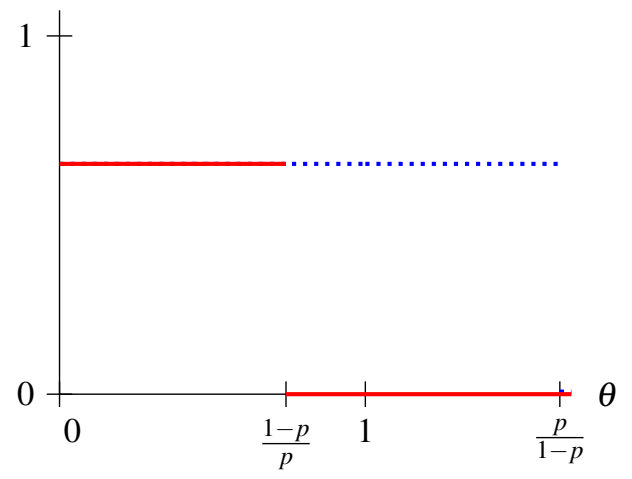

(b) Publicly owned firm $(\omega \geq \gamma)$

Figure 3: The tax auditor's audit strategy as a function of $\theta . \theta$ measures the tax auditor's incentives (as defined in Proposition 1). With increasing $\theta$ the tax auditor's incentives decrease. The dotted line depicts the audit probability for report $(\bar{b}, t)$ (denoted with $\left.\alpha^{f}\right)$, the solid line represents the audit probability for report $(\underline{b}, t)\left(\beta^{f}\right)$.

Some interesting properties of the equilibrium in proposition 2 should be noted:

1. Mills and Sansing (2000) derive a mixed strategy equilibrium in a similar setting. Two differences between our and their model imply different results: (1) In Mills and Sansing (2000), the taxpayer has no chance to understate the financial statement valuation. Instead, he always reports the financial statement valuation truthfully. (2) Variations in the correlation between financial statement and tax valuation are not discussed, because the correlation is restricted by assumption.

2. The equilibrium will be equivalent to the scenario without observable financial statement valuation (see proposition 1) if $p \rightarrow 0.5$. In this case, financial statement information has no information content for the tax auditor, because taxand financial statement valuation are not correlated.

3. The informativeness of the book value $b$ with respect to the tax valuation $t$ 
(driven by $p$ ) determines the taxpayer's reporting strategy. On the one hand, an increase of $p$ implies a low ex - ante probability of type $\bar{b}, \underline{t}$. Thus, the tax auditor will only be indifferent between auditing and not auditing report $(\bar{b}, \underline{t})$, if type $\bar{b}, \bar{t}$ misreports his tax valuation with a moderate probability. This explains $\phi^{\prime}(p)<0$. On the other hand, a higher $p$ allows more frequent misreporting of $\underline{b}, \underline{t}$, because the a priori probability for type $\underline{b}, \underline{t}$ increases. Thus, $\eta^{\prime}(p)>0$ and $v^{\prime}(p)>0$. Note that also the range of nontrivial equilibria $\theta<\frac{p}{1-p}$ extends with increasing $p$.

4. The ex-ante probability of misreporting as a measure of tax evasion is defined as

$$
\begin{aligned}
\mathrm{TE} & =0.5 p(\operatorname{Prob}\{(\hat{b}, \hat{t})=(\underline{b}, \underline{t}) \mid \bar{b}, \bar{t}\}+\operatorname{Prob}\{(\hat{b}, \hat{t})=(\bar{b}, \underline{t}) \mid \bar{b}, \bar{t}\}) \\
& +0.5(1-p) \operatorname{Prob}\{(\hat{b}, \hat{t})=(\underline{b}, \underline{t}) \mid \underline{b}, \bar{t}\} .
\end{aligned}
$$

In case of unobservable financial statements, we obtain

$$
\mathrm{TE}^{o}= \begin{cases}0.5 \theta, & \text { if } \theta \leq 1 \\ 0.5, & \text { if } \theta>1\end{cases}
$$

Observable financial statements imply

(a) $\mathrm{TE}^{f}=\mathrm{TE}^{o}$ in case of a private firm and

(b) $\mathrm{TE}^{f}= \begin{cases}0.5 \theta & \text { if } \theta \leq \frac{1-p}{p} \\ 0.5(1-p)(1+\theta) & \text { if } \frac{1-p}{p}<\theta \leq \frac{p}{1-p} \\ 0.5, & \text { if } \theta>\frac{p}{1-p}\end{cases}$ in case of a publicly listed firm.

The additional information provided by the financial statements only reduces $\mathrm{TE}$, if the taxpayer has a sufficiently strong interest in the financial statement valuation. In case of a private firm with less relevant financial statements, taxpayers compensate the informative financial statement signal by underreporting 
both valuations. As a result, TE remains unchanged.

5. The tax audit probability of a report with positive book-tax differences $\left(\alpha^{f}\right)$ is greater or equal to the tax audit probability of a report without book-tax differences $\left(\beta^{f}\right)$. This is in line with previous evidence demonstrating a positive correlation between tax audit adjustments and positive book-tax differences (Mills 1996, Mills and Sansing 2000).

\subsection{Financial statement valuation and statutory auditor's report on deferred taxes observable}

In the third step, we assume that both financial statement valuation and the statutory auditor's report on deferred taxes are observable to the tax auditor. The following proposition states the equilibrium strategies in this case.

Proposition 3 Let $\lambda \geq \frac{\gamma \Delta}{\gamma \Delta+S}$ and define $\bar{\theta}_{1}=\frac{1-p}{p}, \quad \bar{\theta}_{2}=\frac{\lambda p}{\lambda p+(1-\mu)(1-p)}$ and $\bar{\theta}_{3}=$ $\frac{\lambda p}{(1-\mu)(1-p)}$. Then the taxpayer's equilibrium strategies are as follows:

Types $\bar{b}, \underline{t}$ and $\underline{b}, \underline{t}$ always report their true valuations. The tax auditor never audits $a$ tax valuation $\bar{t}$.

In case of a private firm $(\omega<\gamma)$, the following probabilities are assigned to types' $\bar{b}, \bar{t}$ and $\underline{b}, \bar{t}$ reporting strategies and the tax auditor's audit strategies upon receiving reports $(\bar{b}, \underline{t}),(\underline{b}, \underline{t})$ and the statutory auditor's deferred tax report: 


\begin{tabular}{l|lll}
\hline & $\theta \leq \bar{\theta}_{1}$ & $\bar{\theta}_{1}<\theta \leq \bar{\theta}_{2}$ & $\bar{\theta}_{2}<\theta \leq \bar{\theta}_{3}$ \\
\hline Type $\bar{b}, \bar{t}$ reports $(\bar{b}, \underline{t})$ & $\phi^{a}=\frac{(1-\mu)(1-p)}{\lambda p} \theta$ & $\phi^{a}$ & $\phi^{a}$ \\
Type $\bar{b}, \bar{t}$ reports $(\underline{b}, \underline{t})$ & 0 & $v^{a}=\theta-\frac{1-p}{p}$ & $v^{a}=1-\phi^{a}$ \\
Type $\bar{b}, \bar{t}$ reports $(\bar{b}, \bar{t})$ & $1-\phi^{a}$ & $1-\phi^{a}-v^{a}$ & 0 \\
\hline Type $\underline{b}, \bar{t}$ reports $(\underline{b}, \underline{t})$ & $\eta^{a}=\frac{p}{1-p} \theta$ & 1 & 1 \\
Type $\underline{b}, \bar{t}$ reports $(\underline{b}, \bar{t})$ & $1-\eta^{a}$ & 0 & 0 \\
\hline Report $(\bar{b}, \underline{t})$, Signal $D$ & $\alpha^{a}=\frac{\gamma \Delta}{\lambda(\gamma \Delta+S)}$ & $\alpha^{a}=\frac{\gamma \Delta}{\lambda(\gamma \Delta+S)}$ & $\alpha^{a}=\frac{\omega \Delta}{\lambda(\gamma \Delta+S)}$ \\
Report $(\bar{b}, \underline{t})$, Signal $C$ & 0 & 0 & 0 \\
Report $(\underline{b}, \underline{t})$ & $\beta^{a}=\frac{\gamma \Delta}{\gamma \Delta+S}$ & $\beta^{a}=\frac{\Delta(\gamma-\omega)}{\gamma \Delta+S}$ & $\beta^{a}=0$ \\
\hline
\end{tabular}

In case of a publicly owned firm $(\omega \geq \gamma)$, the reporting and audit strategies are

\begin{tabular}{l|ll}
\hline & $\theta \leq \bar{\theta}_{1}$ & $\bar{\theta}_{1}<\theta \leq \bar{\theta}_{3}$ \\
\hline Type $\bar{b}, \bar{t}$ reports $(\bar{b}, \underline{t})$ & $\phi^{a}=\frac{(1-\mu)(1-p)}{\lambda p} \theta$ & $\phi^{a}$ \\
Type $\bar{b}, \bar{t}$ reports $(\bar{b}, \bar{t})$ & $1-\phi^{a}$ & $1-\phi^{a}$ \\
\hline Type $\underline{b}, \bar{t}$ reports $(\underline{b}, \underline{t})$ & $\eta^{a}=\frac{p}{1-p} \theta$ & 1 \\
Type $\underline{b}, \bar{t}$ reports $(\underline{b}, \bar{t})$ & $1-\eta^{a}$ & 0 \\
\hline Report $(\bar{b}, \underline{t})$, Signal $D$ & $\alpha^{a}=\frac{\gamma \Delta}{\lambda(\gamma \Delta+S)}$ & $\alpha^{a}=\frac{\gamma \Delta}{\lambda(\gamma \Delta+S)}$ \\
Report $(\bar{b}, \underline{t})$, Signal $C$ & 0 & 0 \\
Report $(\underline{b}, \underline{t})$ & $\beta^{a}=\frac{\gamma \Delta}{\gamma \Delta+S}$ & $\beta^{a}=0$ \\
\hline
\end{tabular}

If $\theta>\frac{\lambda p}{(1-\mu)(1-p)}$, both types $\bar{b}, \bar{t}$ and $\underline{b}, \bar{t}$ always report $\underline{t}$ and the tax auditor never audits.

Proof: See appendix.

As a difference to proposition 2, the taxpayer's and the tax auditor's strategies are not only driven by the tax auditor's incentives and the conformity of tax and financial statement valuation, but also by the statutory auditor's tax competence represented by the likelihood ratio $\frac{\lambda}{1-\mu}$. 
It is obvious that the reporting behaviour of type $\underline{b}, \bar{t}$ is not affected by the statutory auditor's assessment on deferred taxes. This is intuitively appealing, because the deferred tax opinion in case of truth telling is irrelevant and a report $(\underline{b}, \underline{t})$ will not induce an auditor's deferred tax evaluation. The main differences arise for taxpayers with $\bar{b}, \bar{t}$ and we will discuss them for private firms first. Figure 4 illustrates the impact of the statutory auditor's report on type $\bar{b}, \bar{t}$ reporting strategies for a private firm.

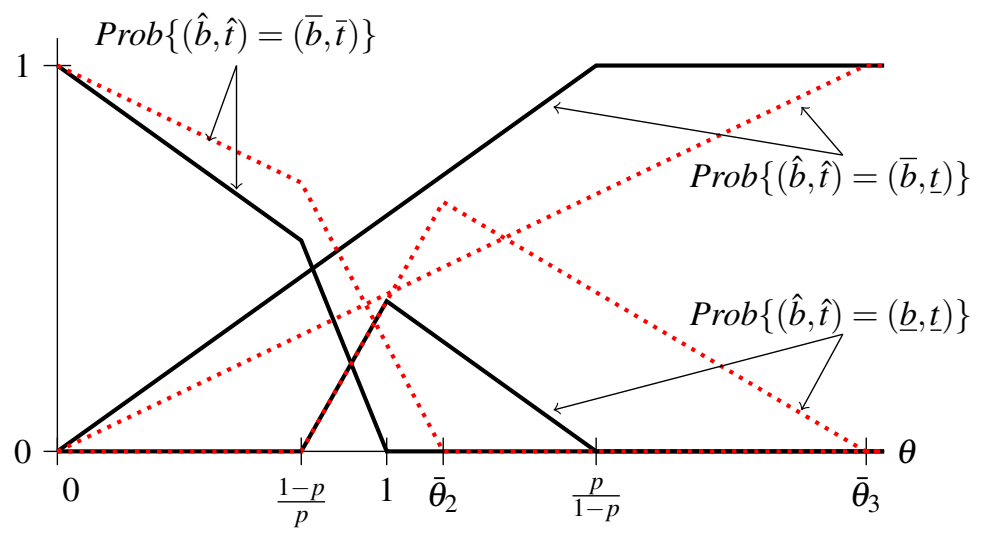

Figure 4: Private firm. Reporting probabilities of type $\bar{b}, \bar{t}$ taxpayers with (dotted lines) and without (solid lines) statutory auditor's report on deferred taxes as a function of $\theta . \theta$ measures the tax auditor's incentives (as defined in Proposition 1). With increasing $\theta$ the tax auditor's incentives decrease. Introducing the statutory auditor's report on deferred taxes increases the probability of a true taxpayer report and the probability of underreporting both tax and financial statement valuation.

Similar to proposition 2, we observe three equilibrium regions. As in proposition 2 , the first region appears for sufficiently high powered tax auditor incentives $\theta<$ $\frac{1-p}{p}$. The figure shows that the probability of truth telling is increased. Intuitively, the deferred tax opinion following report $(\bar{b}, \underline{t})$ reduces the attractivity to misreport. The second region is valid for mid-level incentives $\frac{1-p}{p}<\theta<\frac{\lambda}{\lambda p+(1-\mu)(1-p)}$. It is easy to see that the report on deferred taxes extends this region, because $\lambda>1-\mu \Leftrightarrow$ $\frac{\lambda}{\lambda p+(1-\mu)(1-p)}>1$. The third region appears for lower powered tax auditor incentives $\frac{\lambda}{\lambda p+(1-\mu)(1-p)} \leq \theta<\frac{\lambda p}{(1-\mu)(1-p)}$. The report on deferred taxes also shifts the valid range for region 3 to the right because $\lambda \geq 1-\mu$ implies $\frac{\lambda p}{(1-\mu)(1-p)}>\frac{p}{1-p}$. The key observation is that the probability of understating both financial and tax valuation increases in both regions. Again, the statutory auditor's report on deferred taxes makes 
a report $(\bar{b}, \underline{t})$ less attractive, but now the taxpayer biases both valuations instead of reporting truthfully.

It is interesting to ask how the statutory auditor's tax competence influences the equilibrium strategies. Proposition 3 reveals that $\lambda$ and $\mu$ only affect the probability of a report $(\bar{b}, \underline{t})$ sent by type $\bar{b}, \bar{t}$ given as $\phi^{a}=\frac{1-\mu}{\lambda} \frac{(1-p)}{p} \theta$. A larger ratio $\frac{1-\mu}{\lambda}$ is equivalent to a less tax competent auditor. Thus, a less informative deferred tax verification increases the taxpayer's incentives to misreport. Moreover, since $v^{a}=1-\phi^{a}$ is the probability of reporting $(\underline{b}, \underline{t})$ in the third equilibrium region, a less tax experienced auditor reduces the taxpayer's propensity to avoid a report on deferred taxes.

The tax reporting strategies of a publicly listed firm are also affected by the statutory auditor's opinion on deferred tax assessment. Figure 5 displays the reporting probabilities of type $\bar{b}, \bar{t}$ taxpayers with and without the opinion.

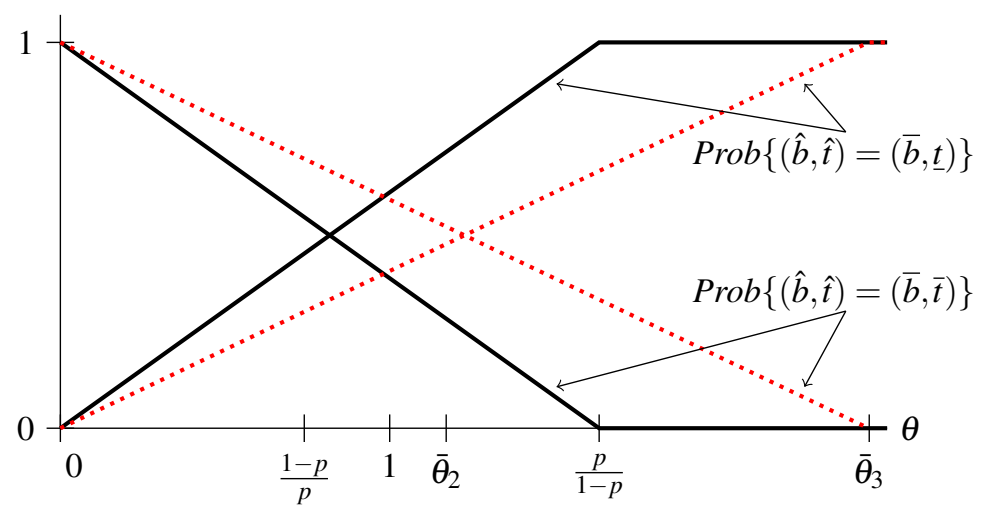

Figure 5: Publicly listed firm. Reporting probabilities of type $\bar{b}, \bar{t}$ taxpayers with (dotted lines) and without (solid lines) statutory auditor's report on deferred taxes as a function of $\theta . \theta$ measures the tax auditor's incentives (as defined in Proposition 1). With increasing $\theta$ the tax auditor's incentives decrease. Introducing the statutory auditor's report on deferred taxes increases the probability of a true report.

It is easy to see that the probability of truthful reporting increases over the whole range of tax auditor incentives. Compared to the private firm setting, publicly listed firms of type $\bar{b}, \bar{t}$ show a significantly larger probability of truthful reporting. Given the observations above, it is intuitively clear that the statutory auditor's assessment of deferred taxes will also reduce tax evasion (TE). We compute the measure as 
1. $\mathrm{TE}^{a}= \begin{cases}0.5 \theta\left(\frac{(1-\mu)(1-p)}{\lambda}+p\right) & \text { if } \theta \leq \bar{\theta}_{2} \\ 0.5 & \text { if } \theta>\bar{\theta}_{2}\end{cases}$

in case of a private firm and

2. $\mathrm{TE}^{a}= \begin{cases}0.5 \theta\left(\frac{(1-\mu)(1-p)}{\lambda}+p\right) & \text { if } \theta \leq \bar{\theta}_{1} \\ 0.5 \theta\left(\frac{(1-\mu)(1-p)}{\lambda}\right)+0.5(1-p) & \text { if } \bar{\theta}_{1}<\theta \leq \bar{\theta}_{3} \\ 0.5 & \text { if } \theta>\bar{\theta}_{3}\end{cases}$ for a publicly listed firm.

Figure 6 compares TE for our three different information environments. The solid (dotted) lines depict TE for private firms (publicly listed firms). The introduction of the statutory auditor's report on deferred taxes reduces TE for both private and publicly listed firms, but the reduction is much more effective in publicly listed firms.

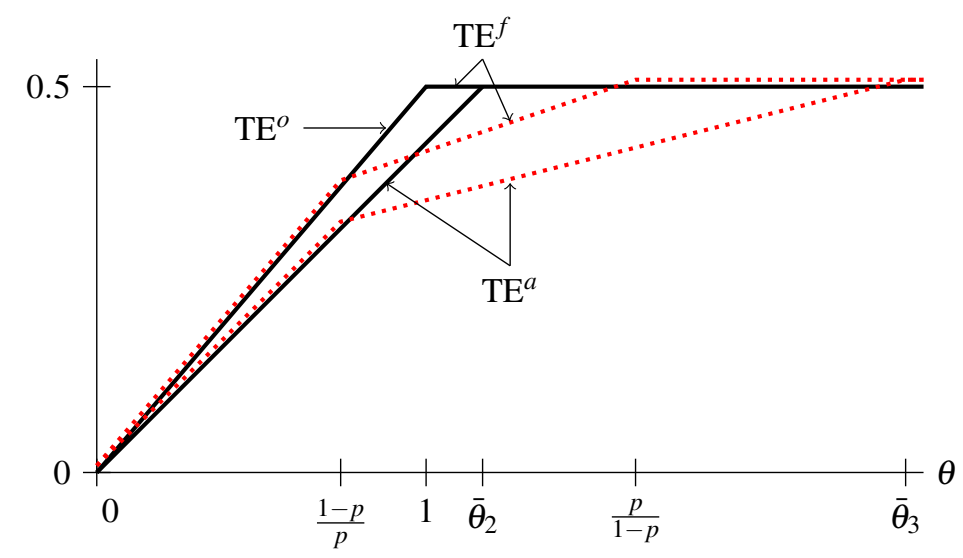

Figure 6: Tax evasion (TE) in private firms (solid lines) and publicly listed firms (dotted lines) with no information $\left(\mathrm{TE}^{o}\right)$, financial statement information $\left(\mathrm{TE}^{f}\right)$ and statutory auditor's report on deferred taxes $\left(\mathrm{TE}^{a}\right)$. Introducing the statutory auditor's report on deferred taxes reduces tax evasion in both private and publicly listed firms. The reduction is more effective in publicly listed firms.

At last, a closer look at the tax audit probabilities shows that the differences between the scenarios with and without deferred tax report stem from differences in the equilibrium regions. The difference between $\alpha^{f}$ and $\alpha^{a}$ within the regions vanishes when we look at the effective audit probability of a report $(\bar{b}, t)$. In the deferred tax report 
scenario, the report $(\bar{b}, \underline{t})$ will only be audited in connection with signal $D$. Thus, the effective audit probabilities are equal, because $\lambda \alpha^{a}=\alpha^{f}$.

In summary, the quality of the statutory auditor's deferred tax review influences the equilibrium via two channels: (1) Misreporting $(\bar{b}, \underline{t})$ becomes more risky. Thus, the $\bar{b}, \bar{t}$ private firm has stronger incentives to understate both tax and financial statement valuation. However, in publicly listed firms the probability of truthful reporting increases. (2) The parameter ranges for equilibria with understated financial statement valuation in private firms increase with the information content of the deferred tax report.

\section{Efficiency implications}

In this section we look at the question how the tax auditor's exploitation of the statutory auditor's deferred tax report influences the efficiency of the tax system. In our model, efficiency has two dimensions:

1. Frequency of tax audits: The audit frequency can be measured by the ex ante probability of a tax audit. We define

$$
\begin{aligned}
\mathrm{TA}^{a}: & =\operatorname{Prob}\{\text { report }=(\bar{b}, \underline{t}) \wedge \sigma=D\} \cdot \alpha^{a}+\operatorname{Prob}\{\operatorname{report}=(\underline{b}, \underline{t})\} \cdot \beta^{a}, \\
\mathrm{TA}^{f}: & =\operatorname{Prob}\{\text { report }=(\bar{b}, \underline{t})\} \cdot \alpha^{f}+\operatorname{Prob}\{\operatorname{report}=(\underline{b}, \underline{t})\} \cdot \beta^{f} \text { and } \\
\mathrm{TA}^{o}: & =\operatorname{Prob}\{\text { report }=\underline{t}\} \cdot \beta^{o}
\end{aligned}
$$

as the tax audit probability in the settings with the statutory auditor's deferred tax report $\left(\mathrm{TA}^{a}\right)$, without deferred tax report but with financial statement information $\left(\mathrm{TA}^{f}\right)$ and without any audit or financial statement information $\left(\mathrm{TA}^{o}\right)$.

2. Tax revenue: We use the probability of taxing a type $\bar{t}$ taxpayer based on a 
reported tax valuation $\underline{t}$ as an (inverse) proxy for tax revenue and define:

$$
\begin{aligned}
\operatorname{TR}^{a}:= & (\operatorname{Prob}\{(\bar{b}, \bar{t}) \text { reports }(\underline{b}, \underline{t})\}+\operatorname{Prob}\{(\underline{b}, \bar{t}) \text { reports }(\underline{b}, \underline{t})\})\left(1-\beta^{a}\right) \\
& +\operatorname{Prob}\{(\bar{b}, \bar{t}) \text { reports }(\bar{b}, \underline{t}) \wedge \sigma=C\} \\
& +\operatorname{Prob}\{(\bar{b}, \bar{t}) \text { reports }(\bar{b}, \underline{t}) \wedge \sigma=D\}\left(1-\alpha^{a}\right) \\
\operatorname{TR}^{f}:= & (\operatorname{Prob}\{(\bar{b}, \bar{t}) \text { reports }(\underline{b}, \underline{t})\}+\operatorname{Prob}\{(\underline{b}, \bar{t}) \text { reports }(\underline{b}, \underline{t})\})\left(1-\beta^{f}\right) \\
& +\operatorname{Prob}\{(\bar{b}, \bar{t}) \operatorname{reports}(\bar{b}, \underline{t})\}\left(1-\alpha^{f}\right) \\
\operatorname{TR}^{o}:= & \operatorname{Prob}\{\bar{t} \text { reports } \underline{t}\}\left(1-\beta^{o}\right) .
\end{aligned}
$$

Note that our TR - measure differs from the tax evasion measure (TE) used in the previous section because TR captures sucessful tax evasion only.

The following two propositions compare both measures for both a publicly listed and a private firm:

Proposition 4 Suppose a publicly listed firm $(\omega>\gamma)$. Comparing the tax audit frequency and the taxation based on misreported tax valuation yields:

\begin{tabular}{l|l|l}
\hline & Tax revenue & Tax audit probability \\
\hline$\theta \leq \frac{1-p}{p}$ & $T R^{a}<T R^{f}=T R^{o}$ & $T A^{a}<T A^{f}=T A^{o}$ \\
$\frac{1-p}{p}<\theta \leq 1$ & $T R^{a}<T R^{f}, T R^{a} \gtreqless T R^{o}, T R^{f} \gtreqless T R^{o}$ & $T A^{a}<T A^{f}<T A^{o}$ \\
$1<\theta \leq \frac{p}{1-p}$ & $T R^{a}<T R^{f}<T R^{o}$ & $T A^{o}<T A^{a}<T A^{f}$ \\
$\frac{p}{1-p}<\theta \leq \frac{\lambda}{1-\mu} \frac{p}{1-p}$ & $T R^{a}<T R^{f}=T R^{o}$ & $T A^{o}=T A^{f}<T A^{a}$ \\
\hline
\end{tabular}

Proof: See appendix.

Three properties of proposition 4 are remarkable:

1. Note that $\mathrm{TA}^{o}=0$ and $\mathrm{TR}^{o}=0.5$ due to the trivial pure strategy equilibrium for $\theta>1$. This explains the rankings with respect to the no-information setting. 
2. An information setting with statutory auditor's report on deferred taxes dominates the scenario with financial statement information only as long as the equilibrium in this scenario is non trivial $\left(\theta \leq \frac{p}{1-p}\right)$, because we observe higher tax revenue and lower audit probability. Thus, providing the informative statutory auditor's report to the tax auditor is efficient. This point is quite intuitive, because the tax auditor can enhance his audit efficiency using the informative signal and, as a reaction, the firm reduces misreporting.

3. For a medium range of tax auditor incentives $\left(\frac{1-p}{p}<\theta \leq 1\right)$, we may encounter higher tax revenues together with a larger audit probability in the no-information setting compared to both other settings.

Proposition 5 Suppose a private firm $(\gamma>\omega)$ and define $\bar{\theta}_{1}=\frac{1-p}{p}, \bar{\theta}_{2}=\frac{\lambda p}{\lambda p+(1-\mu)(1-p)}$ and $\bar{\theta}_{3}=\frac{\lambda p}{(1-\mu)(1-p)}$. Comparing the tax audit frequency and the taxation based on misreported tax valuation yields:

\begin{tabular}{l|l|l}
\hline & Tax revenue & Tax audit probability \\
\hline$\theta \leq \bar{\theta}_{1}$ & $T R^{a}<T R^{f}=T R^{o}$ & $T A^{a}<T A^{f}=T A^{o}$ \\
$\bar{\theta}_{1}<\theta \leq 1$ & $T R^{a}<T R^{f}, T R^{a} \gtreqless T R^{o}, T R^{f}>T R^{o}$ & $T A^{a}<T A^{f}<T A^{o}$ \\
$1 \leq \theta \leq \min \left\{\frac{p}{1-p}, \bar{\theta}_{2}\right\}$ & $T R^{a} \gtreqless T R^{f}<T R^{o}$ & $T A^{o}<T A^{a} \gtreqless T A^{f}$. \\
$\min \left\{\frac{p}{1-p}, \bar{\theta}_{2}\right\} \leq \theta \leq \frac{p}{1-p}$ & $T R^{f}<T R^{a}<T R^{o}$ & $T A^{o}<T A^{a}<T A^{f}$. \\
$\frac{p}{1-p} \leq \theta \leq \bar{\theta}_{3}$ & $T R^{a}<T R^{f}=T R^{o}$ & $T A^{a}>T A^{f}=T A^{o}$. \\
\hline
\end{tabular}

In case of $1 \leq \theta \leq \min \left\{\frac{p}{1-p}, \bar{\theta}_{2}\right\}, T A^{a} \geq T A^{f}$ and $T R^{a}>T R^{f}$ never appear simultaneously.

Proof: See appendix.

Proposition 5 reveals some interesting properties:

1. The efficiency result from proposition 4 remains valid for private firms in a situation with high powered tax auditor incentives $\left(\theta<\frac{1-p}{p}\right)$. 
2. In a situation with medium tax auditor incentives $\left(\frac{1-p}{p}<\theta \leq 1\right)$ we observe $\mathrm{TR}^{f}>\mathrm{TR}^{o}$ for a private firm instead of $\mathrm{TR}^{f} \gtreqless \mathrm{TR}^{o}$ for a publicly listed firm. Private firms exhibit lower tax revenues because type $\bar{b}, \bar{t}$ starts to underreport both financial and tax valuation. Note, however, that the statutory auditor's report on deferred taxes is still efficient compared to the setting without report.

3. Significant differences to the publicly listed firm setting arise in case of a tax auditor with lower powered incentives. Now, the efficiency of the statutory auditor's report will not remain valid. The report will either imply a lower tax audit probability at the cost of lower tax revenue or higher tax revenue at the cost of a higher tax audit frequency. However, proposition 5 states that the report will never be dominated. The most surprising point here is that an informative signal over deferred taxes can increase the probability of a false tax base. A closer look at proposition 5 shows that $\mathrm{TR}^{a}>\mathrm{TR}^{f}$ especially appears at the scenario, where type $\bar{b}, \bar{t}$ mixes between the two misreports $(\bar{b}, \underline{t})$ and $(\underline{b}, \underline{t})$. The deferred tax signal increases the probability of reporting $(\underline{b}, \underline{t})$ in order to avoid the signal. But the tax auditor challenges report $(\underline{b}, \underline{t})$ with a low or with zero probability. As a consequence, a lower audit probability comes together with a higher probability of a false tax base.

The figures 7 and 8 illustrate the key properties of propositions 4 and 5. The dashed line represents the scenario with an observable statutory auditor report on deferred taxes, the solid line the scenario without such a report but with financial statement information and the dotted line the no - information scenario.

The numerical example in figure 7 is such that the audit probability for both private and publicly listed firms is strictly lower in the regime with observable report on deferred taxes as long as any tax audit occurs in the regime without deferred tax review. Moreover, the figure shows that the ex ante audit probability jumps down when the equilibrium regions given in propositions 2 and 3 change. Within these regions, how- 


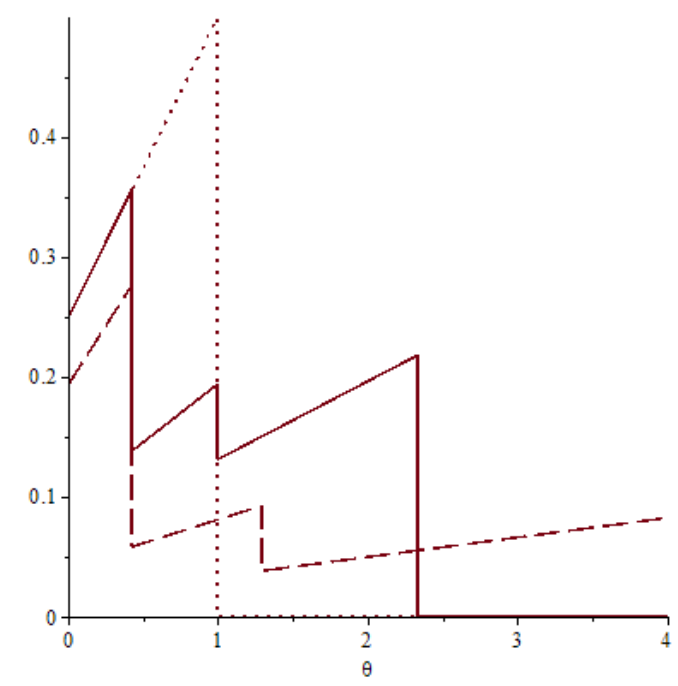

(a) Private firm $(\gamma>\omega)$

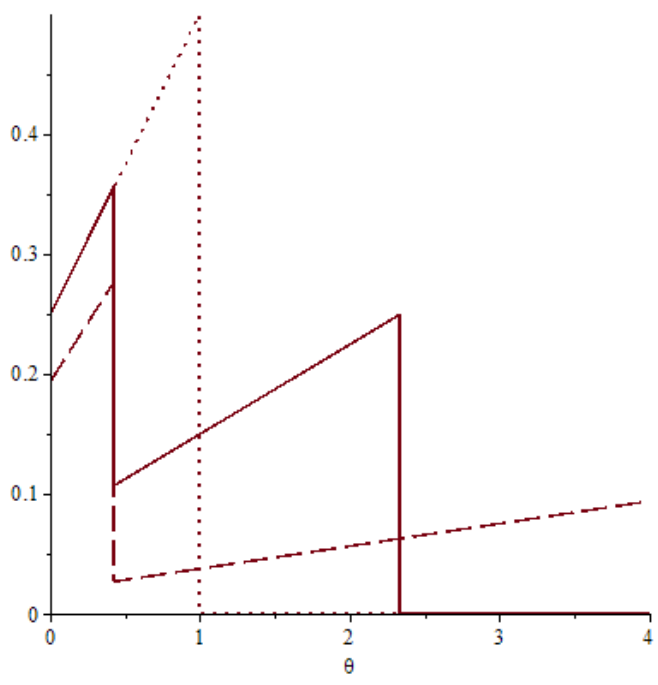

(b) Publicly listed firm $(\omega \geq \gamma)$

Figure 7: Ex ante probability of a tax audit $\mathrm{TA}^{o}$ (dotted line), $\mathrm{TA}^{f}$ (solid line) and $\mathrm{TA}^{a}$ (dashed line) as a function of $\theta$. $\theta$ measures the tax auditor's incentives (as defined in Proposition 1). With increasing $\theta$ the tax auditor's incentives decrease. Parameter values used: $p=0.7, \gamma=0.4$, $\omega=0.35$ for private firms, $\omega>0.4$ for publicly listed firms, $\Delta=100, \lambda=\mu=0.8, S=40$.

ever, $\mathrm{TA}^{a}$ and $\mathrm{TA}^{f}$ increase with lower powered tax auditor incentives $(\theta \uparrow)$. The reason is simple: The probabilities of the reports $(\bar{b}, \underline{t})$ or $(\underline{b}, \underline{t})$ are increasing in $\theta$ while $\alpha$ and $\beta$ are constant.

The probability of a false taxation base $\left(\mathrm{TR}^{a}, \mathrm{TR}^{f}\right.$ and $\left.\mathrm{TR}^{o}\right)$ for private and publicly listed firms is depicted in figure 8. In case of a private firm, we observe an interval for $\theta$, where the probability of false taxation increases when the audit report concerning deferred taxes becomes available. Moreover, in case of a private firm, the positive relation between the audit probability and $\theta$ within the equilibrium regions depicted in figure 7 does not always go along with an increase of the false taxation base probability. For $\theta>1$, for example, lower powered incentives increase the frequency of reporting $(\bar{b}, \underline{t})$ instead of $(\underline{b}, \underline{t})$. Again, this is due to the type $\bar{b}, \bar{t}$, whose underreporting probability increases with $\theta$. Since the tax auditor does not challenge the downward biased report $(\underline{b}, \underline{t})$, but audits $(\bar{b}, \underline{t})$ with $\alpha>0$, the probability of a taxation based on a misreported valuation decreases in $\theta$. 


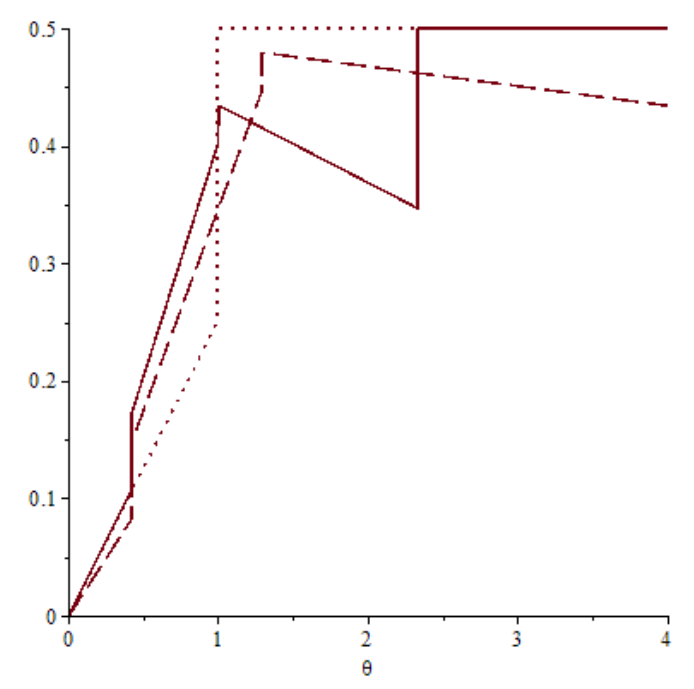

(a) Private firm $(\gamma>\omega)$

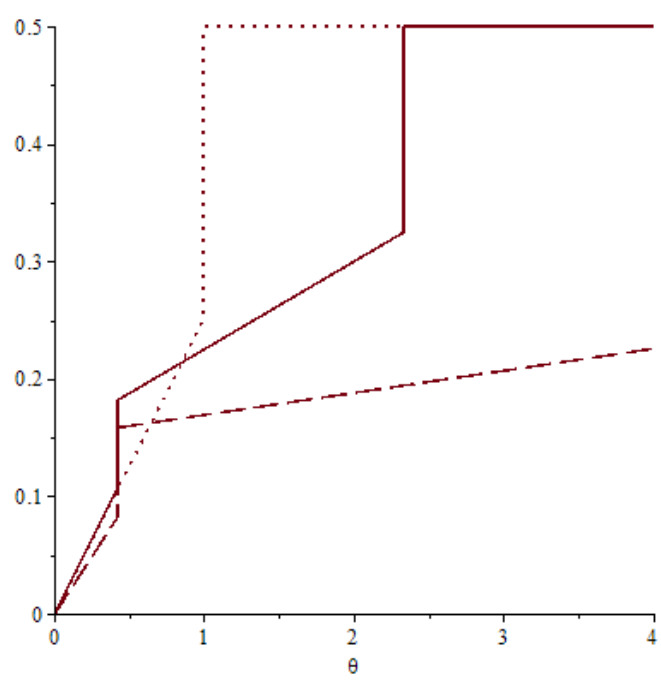

(b) Publicly listed firm $(\omega \geq \gamma)$

Figure 8: Probability of a false tax base $\mathrm{TR}^{o}$ (dotted line), $\mathrm{TR}^{f}$ (solid line) and $\mathrm{TR}^{a}$ (dashed line) as a function of $\theta$. $\theta$ measures the tax auditor's incentives (as defined in Proposition 1). With increasing $\theta$ the tax auditor's incentives decrease. Parameter values used: $p=0.7, \gamma=0.4$, $\omega=0.35$ for private firms, $\omega>0.4$ for publicly listed firms, $\Delta=100, \lambda=\mu=0.8, S=40$.

We shall conclude this section with some comparative statics. We concentrate on the influence of conformity, managerial incentives regarding tax and financial statement valuation and the statutory auditor's tax competence on the tax revenue measure. Table 1 presents the comparative statics of the measure TR for publicly listed firms.

\begin{tabular}{c|cc|cc|c}
\hline$\theta$ & $\frac{\partial \mathrm{TR}^{f}}{\partial p}$ & $\frac{\partial \mathrm{TR}^{a}}{\partial p}$ & $\frac{\partial \mathrm{TR}^{f}}{\partial \gamma}$ & $\frac{\partial \mathrm{TR}^{a}}{\partial \gamma}$ & $\frac{\partial \mathrm{TR}^{a}}{\partial R}$ \\
\hline \hline$\left[0, \frac{1-p}{p}\right)$ & $(0)$ & $(+)$ & $(-)$ & $(-)$ & $(+)$ \\
{$\left[\frac{1-p}{p}, 1\right)$} & $(-)$ & $(-)$ & $(-)$ & $(-)$ & $(+)$ \\
{$\left[1, \frac{p}{1-p}\right)$} & $(-)$ & $(-)$ & $(-)$ & $(-)$ & $(+)$ \\
{$\left[\frac{p}{1-p}, \frac{1}{R} \frac{p}{1-p}\right)$} & $(0)$ & $(-)$ & $(-)$ & $(-)$ & $(+)$ \\
\hline
\end{tabular}

Table 1: Public firms: Influence of conformity $(p)$, managerial preferences for tax savings $(\gamma)$, and statutory auditor's tax competence $\left(R=\frac{1-\mu}{\lambda}\right)$ on the tax revenue measure TR. $\theta$ measures the tax auditor's incentives (as defined in Proposition 1). With increasing $\theta$ the tax auditor's incentives decrease. Remember that TR is an inverse measure for tax revenues.

We observe that the influence of $R=\frac{1-\mu}{\lambda} \in(0,1]$ is as expected. Increasing $R \rightarrow 1$ means a statutory auditor with almost no tax competence and, thus, a higher probability 
of a false taxation base meaning higher tax revenue.

The negative influence of $\gamma$ on the false taxation base is due to the strategic tax auditor he increases the audit probability of a low tax valuation with a higher incentive weight for the tax valuation.

Conformity will decrease tax revenue (increases false taxation base probability) if tax auditor incentives are high powered (low $\theta$ ) and a deferred tax report is provided: Generally, higher conformitiy increases type $\underline{b}, \bar{t}$ probability of reporting $(\underline{b}, \underline{t})$ and decreases type $\bar{b}, \bar{t}$ probability to report $(\bar{b}, \underline{t})$. These two effects are exactly equal in case of no deferred tax report. Introducing the deferred tax report dampens type $\bar{b}, \bar{t}$ probability to report $(\bar{b}, \underline{t})$ by the factor $R<1$. Thus, the underreporting incentive of type $\underline{b}, \bar{t}$ dominates. When tax auditor incentives become weaker, type $\underline{b}, \bar{t}$ always underreports and the increased truthful reporting incentive for type $\bar{b}, \bar{t}$ induced by higher $p$ remains.

\begin{tabular}{c|cc|cc|cc|c}
\hline$\theta$ & $\frac{\partial \mathrm{TR}^{f}}{\partial p}$ & $\frac{\partial \mathrm{TR}^{a}}{\partial p}$ & $\frac{\partial \mathrm{TR}^{f}}{\partial \gamma}$ & $\frac{\partial \mathrm{TR}^{a}}{\partial \gamma}$ & $\frac{\partial \mathrm{TR}^{f}}{\partial \omega}$ & $\frac{\partial \mathrm{TR}^{a}}{\partial \omega}$ & $\frac{\partial \mathrm{TR}^{a}}{\partial R}$ \\
\hline$\left[0, \frac{1-p}{p}\right)$ & $(0)$ & $(+)$ & $(-)$ & $(-)$ & $(0)$ & $(0)$ & $(+)$ \\
{$\left[\frac{1-p}{p}, 1\right)$} & $(+)$ & $(+)$ & $(-)$ & $(-)$ & $(+)$ & $(+)$ & $(+)$ \\
{$\left[1, \min \left\{\bar{\theta}_{2}, \frac{p}{1-p}\right\}\right)$} & $(+)$ & $(+)$ & $(+)$ & $(-)$ & $(-)$ & $(+)$ & $(+)$ \\
{$\left[\min \left\{\bar{\theta}_{2}, \frac{p}{1-p}\right\}, \frac{p}{1-p}\right)$} & $(+)$ & $(+)$ & $(+)$ & $(+)$ & $(-)$ & $(-)$ & $(-)$ \\
{$\left[\frac{p}{1-p}, \bar{\theta}_{3}\right)$} & $(0)$ & $(+)$ & 0 & $(+)$ & 0 & $(-)$ & $(-)$ \\
\hline
\end{tabular}

Table 2: Private firms: Influence of conformity $(p)$, managerial preferences for tax $(\gamma)$ and financial statement $(\omega)$ valuation, and statutory auditor's tax competence $\left(R=\frac{1-\mu}{\lambda}\right)$ on the tax revenue measure TR. $\theta$ measures the tax auditor's incentives (as defined in Proposition 1). With increasing $\theta$ the tax auditor's incentives decrease. Remember that TR is an inverse measure for tax revenues.

Table 2 shows the comparative static results for private firms. The first observation refers to the influence of conformity. As a difference to the publicly listed firms, increased conformity has a negative impact on the tax revenue of private firms. The probability of a false taxation base increases because type $\bar{b}, \bar{t}$ in a private firm has stronger incentives to underreport both financial statement and tax valuation with higher conformity. This observation is in contrast to previous literature which usually assumes 
that conformity increases tax compliance (see for a discussion, e.g., Chan et al. (2010) and Blaylock et al. (2014)). However, prior empirical studies that find a positive link between book-tax conformity and tax compliance are based on public firm samples only (Chan et al. 2010, Atwood et al. 2012, Tang 2015). For public firms, we also find a positive relation between book-tax conformity and tax compliance when tax auditors are not highly incentivized (see Table 1). One should, however, not generalize these empirical findings to private firms because our model predicts the opposite tax compliance effect for private firms.

The second observation is a change of sign in the impact of the incentive weights $\gamma$ and $\omega$. For high powered auditor incentives higher tax valuation incentives increase the audit probabiliy and lower the false taxation base probability. The opposite is true for increased financial statement valuation incentives, because they make underreporting both valuations less attractive and, thus, decrease the audit probability of report $\underline{b}, \underline{t}$. For low powered tax auditor incentives, the impact of $\omega$ and $\gamma$ on the equilibrium audit probability for report $(\bar{b}, t)$ reverses. A stronger incentive weight on the financial statement valuation (tax valuation) decreases (increases) the probability of a false taxation base.

As a last difference to the publicly listed firms, also the impact of statutory auditor's tax competence changes the sign when the tax auditor's incentives are low powered.

For $\theta \geq \frac{p}{1-p}$, higher tax competence of the statutory auditor (lower $R$ ) shifts reporting from the report $(\bar{b}, \underline{t})$, which is audited with positive probability, to the report $(\underline{b}, \underline{t})$, which will never be audited in equilibrium. Therefore, the statutory auditor's higher tax competence implies lower tax revenue.

\section{Summary and concluding remarks}

We integrate two novel features in a tax reporting game: In the first modification of a standard inspection game, the tax auditor can observe the financial statements audited 
by a statutory auditor. The statutory auditor perfectly verifies potential overstatements but never corrects potential understatements. Thus, firms can misreport both their book and their tax income. We then extend this model by assuming that the tax auditor additionally receives a report from the statutory auditor concerning deferred taxes. The report is an informative signal of the true tax valuation of the firm. Our main interest is in how the additional signal regarding tax valuation influences the equilibrium properties of our tax reporting game and the efficiency of the tax system. One would expect that a tax system with an additional informative signal is efficient with respect to tax audit costs and tax revenue. Our results show that this intuition is not necessarily true. The review of deferred taxes and the observability of financial accounting information may induce private firms to avoid the signal by underreporting both their financial statement and tax valuation. This reaction can reduce the tax revenue generated by the tax system. Moreover, if tax policy increases book-tax conformity, our model predicts lower tax revenues from private firms. In contrast, tax revenues from public firms increase with higher book-tax conformity if tax auditors are not highly incentivized, and public firms, in general, reduce their tax evasion in response to the observability of financial accounting information and audit reports. 


\section{References}

[1] Allingham, M. G.; Sandmo, A. (1972): Income Tax Evasion: A Theoretical Analysis, Journal of Public Economics 1 (3/4), 323-338.

[2] Atwood, T. J.; Drake, M. S.; Myers, J. N.; Myers, L. A. (2012). Home country tax system characteristics and corporate tax avoidance: International evidence, The Accounting Review, 87(6), 1831-1860.

[3] Bayer, R.-C. (2006): A contest with the taxman - the impact of tax rates on tax evasion and wastefully invested resources, European Economic Review 50 (5), 1071-1104.

[4] Beck, P. J.; Davis, J. S.; Jung, W.-O. (1996): Tax Advice and Reporting under Uncertainty: Theory and Experimental Evidence, Contemporary Accounting Research 13 (1), 49-80.

[5] Beck, P. J.; Davis, J. S.; Jung, W.-O. (2000): Taxpayer Disclosure and Penalty Laws, Journal of Public Economic Theory 2 (2), 243-272.

[6] Beck, P. J.; Jung, W.-O. (1989): Taxpayers' Reporting Decisions and Auditing under Information Asymmetry, The Accounting Review 64 (3), 468-487.

[7] Beuselinck, C., Deloof, M.,; Vanstraelen, A. (2015): Cross-jurisdictional income shifting and tax enforcement: evidence from public versus private multinationals, Review of Accounting Studies, 20(2), 710-746.

[8] Blaylock, B.; Gaertner, F.; Shevlin, T. (2014): The association between book-tax conformity and earnings management, Review of Accounting Studies, 1-32.

[9] Center on Budget and Policy Priorities (2016): IRS Funding Cuts Compromise Taxpayer Service and Weaken Enforcement, http://www.cbpp.org/research/federal-tax/. 
[10] Chan, K. H.; Lin, Kenny Z.; Mo, Phyllis L. L. (2010): Will a departure from tax-based accounting encourage tax noncompliance? Archival evidence from a transition economy, Journal of Accounting and Economics 50 (1), 58-73.

[11] Erard, B.; Feinstein, J. S. (1994): Honesty and Evasion in the Tax Compliance Game, The RAND Journal of Economics 25 (1), 1-19.

[12] Francis, J. R.; Krishnan, J. (1999): Accounting Accruals and Auditor Reporting Conservatism, Contemporary Accounting Research, 16 (1), 135-165.

[13] Graetz, M. J.; Reinganum, J. F.; Wilde, L. L. (1986): The Tax Compliance Game: Toward an Interactive Theory of Law Enforcement, Journal of Law, Economics, and Organization 2 (1), 1-32.

[14] Lynch, D.; Romney, M. A.; Stomberg, B.; Wangerin, D. (2017). Trade-Offs between Tax and Financial Reporting Benefits: Evidence from Purchase Price Allocations in Taxable Acquisitions, available at SSRN.

[15] Mills, L. F. (1996): Corporate tax compliance and financial reporting, National Tax Journal, 421-435.

[16] Mills, L. F. (1998): Book-tax differences and Internal Revenue Service adjustments, Journal of Accounting Research, 36(2), 343-356.

[17] Mills, L. F.; Newberry, K. J. (2001): The influence of tax and nontax costs on book-tax reporting differences: Public and private firms, Journal of the American Taxation Association, 23(1), 1-19.

[18] Mills, L. F.; Robinson, L. A.; Sansing, R. C. (2010): FIN 48 and Tax Compliance, The Accounting Review 85 (5), 1721-1742.

[19] Mills, L. F.; Sansing, R. C. (2000): Strategic Tax and Financial Reporting Decisions: Theory and Evidence, Contemporary Accounting Research 17 (1), 85-106. 
[20] Reinganum, J. F.; Wilde, L. L. (1986): Equilibrium Verification and Reporting Policies in a Model of Tax Compliance, International Economic Review 27 (3), 739-760.

[21] Reinganum, J. F.; Wilde, L. L. (1988): A Note on Enforcement Uncertainty and Taxpayer Compliance, The Quarterly Journal of Economics 103 (4), 793-798.

[22] Rhoades, S. C. (1999): The Impact of Multiple Component Reporting on Tax Compliance and Audit Strategies, The Accounting Review 74 (1), 63-85.

[23] Sansing, R. C. (1993): Information Acquisition in a Tax Compliance Game, The Accounting Review 68 (4), 874-884.

[24] Simone, L.; Sansing, R. C.; Seidman, J. K. (2013): When are Enhanced Relationship Tax Compliance Programs Mutually Beneficial?, The Accounting Review 88 (6), 1971-1991.

[25] Slemrod, J. (2016). Tax compliance and enforcement: New research and its policy implications, available at SSRN.

[26] Tang, T. Y. (2015): Does book-tax conformity deter opportunistic book and tax reporting? An international analysis, European Accounting Review, 24(3), 441469. 


\section{Appendix}

\subsection{Legal obligations: Overview}

\begin{tabular}{|c|c|c|}
\hline Country & $\begin{array}{l}\text { Obligation to file financial ac- } \\
\text { counting statements together } \\
\text { with the tax return }\end{array}$ & $\begin{array}{l}\text { Obligation to file the audit report } \\
\text { together with the tax return }\end{array}$ \\
\hline Australia & Yes & $\mathrm{No}^{3}$ \\
\hline Austria & Yes & No \\
\hline Belarus & Yes & No \\
\hline Belgium & No & Yes \\
\hline Brazil & Yes & No \\
\hline Canada & Yes & No \\
\hline China & Yes & $\mathrm{No}^{3}$ \\
\hline Czech Republic & Yes & No \\
\hline Denmark & Yes & No \\
\hline Estonia & No & No \\
\hline Finland & Yes & No \\
\hline Germany & Yes & Yes \\
\hline Hong Kong & Yes & Yes \\
\hline Hungary & No & No \\
\hline Ireland & Yes & Yes \\
\hline Italy & No & No \\
\hline Yespan & Yes & No \\
\hline Korea & No & No \\
\hline Luxembourg & Yes & No \\
\hline Netherlands & No & No \\
\hline Panama & No & No \\
\hline Poland & Yes $^{1}$ & Yes \\
\hline Russia & Yes & $\mathrm{No}^{3}$ \\
\hline Slovakia & No & No \\
\hline South Africa & Yes & Yes \\
\hline Spain & Yes & $\mathrm{No}^{2}$ \\
\hline Sweden & No & No \\
\hline Switzerland & Yes & $\mathrm{No}^{3}$ \\
\hline Ukraine & Yes & No \\
\hline United Kingdom & Yes & Yes \\
\hline Uruguay & No & No \\
\hline USA & No & No \\
\hline Vietnam & Yes & Yes \\
\hline
\end{tabular}

${ }^{1}$ Non-audited financial statements do not need to be filed.

2 The audit report is a publicly available information.

${ }^{3}$ Survey respondents state that in practice the audit report is often enclosed along with the financial statements or that the Revenue Agency may request this as part of tax audits.

Table 3: Legal obligations to file financial accounting statements and statutory auditor reports to the tax administration. Data source: Own survey conducted between March and June 2016 among tax managers, directors, and partners of PricewaterhouseCoopers.

\subsection{Proof of proposition 1}

The tax auditor's equilibrium audit probability can be derived from the indifference of type $\bar{t}$ taxpayer between truthful reporting and report $\underline{t}$. Reformulating

$$
\gamma \bar{t}=\beta^{o}(\gamma \bar{t}+S)+\left(1-\beta^{o}\right) \gamma \underline{t}
$$


yields

$$
\beta^{o}=\frac{\gamma \Delta}{\gamma \Delta+S}
$$

Type $\bar{t}$ taxpayer's reporting strategy $\theta=\frac{K_{S}}{\delta \Delta-K_{S}}$ is obtained by rearranging

$$
\frac{\theta}{1+\theta}\left(\delta \Delta-K_{S}\right)+\frac{1}{1+\theta}\left(-K_{S}\right)=0 .
$$

\subsection{Proof of proposition 2}

We prove the equilibrium for each of the regions given in proposition 2 in two steps. In the first step, we derive the tax auditor's and the type $\bar{t}$ - taxpayer's equilibrium probabilities. In the second step, we check the conditions under which the equilibrium is valid. We start with the private firm characterized by $\gamma>\omega$.

Region 1: $\theta<\frac{1-p}{p}$.

Step 1: The probability $\beta^{f}$ will be set such that type $\underline{b}, \bar{t}$ is indifferent between truthful reporting and report $(\underline{b}, \underline{t})$. We obtain

$$
\begin{aligned}
& \omega \underline{b}-\gamma \bar{t}=\beta^{f}(\omega \underline{b}-\gamma \bar{t}-S)+\left(1-\beta^{f}\right)(\omega \underline{b}-\gamma \underline{t}) \\
& \Leftrightarrow \quad \beta^{f}=\frac{\gamma \Delta}{\gamma \Delta+S} .
\end{aligned}
$$

Also type $\bar{b}, \bar{t}$ must be indifferent between report $(\bar{b}, \bar{t})$ and $(\bar{b}, t)$. Therefore, the probability $\alpha^{f}$ can be determined by

$$
\begin{aligned}
\omega \bar{b}-\gamma \bar{t} & =\alpha^{f}(\omega \bar{b}-\gamma \bar{t}-S)+\left(1-\alpha^{f}\right)(\omega \bar{b}-\gamma \underline{t}) \\
\Leftrightarrow \quad \alpha^{f} & =\frac{\gamma \Delta}{\gamma \Delta+S} .
\end{aligned}
$$

The reporting strategy of type $\bar{b}, \bar{t}$ is given by $\phi=\frac{1-p}{p} \theta$ and results from the tax auditor's indifference between auditing and not auditing after observing report $(\bar{b}, \underline{t})$

$$
\frac{\phi p}{\phi p+(1-p)}\left(\delta \Delta-K_{S}\right)-\frac{1-p}{\phi p+(1-p)} K_{S}=0 .
$$

The tax auditor is also indifferent between auditing and not auditing the report $(\underline{b}, \underline{t})$. Thus,

$$
\frac{(1-p) \eta}{p+(1-p) \eta}\left(\delta \Delta-K_{S}\right)+\frac{p}{p+(1-p) \eta}\left(-K_{S}\right)=0 \Leftrightarrow \eta=\frac{p}{1-p} \theta .
$$


Step 2: We have to check the following conditions:

1. Clearly, $0<\alpha^{f}, \beta^{f}<1$. Moreover, $\eta>0$ and $\phi>0$ because of $\delta \Delta-K_{S}>0$.

2. $\eta \leq 1 \Leftrightarrow \theta \leq \frac{1-p}{p}$. Obviously, $\eta<1$ implies $\phi<1$.

3. Type $\bar{b}, \bar{t}$ will never report $(\underline{b}, \underline{t})$ because $\alpha^{f}=\beta^{f}$ and $\omega \underline{b}<\omega \bar{b}$.

Region 2: $\frac{1-p}{p}<\theta \leq 1$.

Step 1: In this region, type $\bar{b}, \bar{t}$ is indifferent between reporting $(\bar{b}, \bar{t}),(\bar{b}, \underline{t})$ and $(\underline{b}, \underline{t})$. This yields

$$
\begin{aligned}
& \left.\omega \bar{b}-\gamma \bar{t}=\alpha^{f}(\omega \bar{b}-\gamma \bar{t}-S)+\left(1-\alpha^{f}\right)(\omega \bar{b}-\gamma \underline{t})\right) \text { and } \\
& \left.\omega \bar{b}-\gamma \bar{t}=\beta^{f}(\omega \underline{b}-\gamma \bar{t}-S)+\left(1-\beta^{f}\right)(\omega \underline{b}-\gamma \underline{t})\right)
\end{aligned}
$$

implying $\alpha^{f}=\frac{\gamma \Delta}{\gamma \Delta+S}$ and $\beta^{f}=\frac{\Delta(\gamma-\omega)}{\gamma \Delta+S}$.

As in region 1, the tax auditor is indifferent between auditing and not auditing the reports $(\underline{b}, \underline{t})$ and $(\bar{b}, \underline{t})$. Solving

$$
\begin{aligned}
\frac{\phi p}{\phi p+(1-p)}\left(\delta \Delta-K_{S}\right)-\frac{1-p}{\phi p+(1-p)} K_{S} & =0 \text { and } \\
\frac{p v+(1-p)}{p v+p+(1-p)}\left(\delta \Delta-K_{S}\right)-\frac{p}{p v+p+(1-p)} K_{S} & =0
\end{aligned}
$$

yields $\phi=\frac{1-p}{p} \theta$ and $v=\theta-\frac{1-p}{p}$.

Step 2: The following conditions have to be checked:

1. $\alpha^{f}, \beta^{f}$, and $\phi \in[0,1]$ because of $\theta<1, \delta \Delta-K_{S}>0$ and $\omega<\gamma$.

2. $\theta>\frac{1-p}{p}$ implies $v>0$. A binding upper bound with respect to $\theta$ can be derived from $v+\phi<1 \Leftrightarrow \theta<1$.

Region 3: $1<\theta \leq \frac{p}{1-p}$.

Step 1: The audit probability $\alpha^{f}$ is such that type $\bar{b}, \bar{t}$ is indifferent between the reports $(\bar{b}, \underline{t})$ and $(\underline{b}, \underline{t})$. Solving

$$
\omega \underline{b}-\gamma \underline{t}=\alpha^{f}(\omega \bar{b}-\gamma \bar{t}-S)+\left(1-\alpha^{f}\right)(\omega \bar{b}-\gamma \underline{t})
$$

yields $\alpha^{f}=\frac{\omega \Delta}{\lambda(\gamma \Delta+S)}$. The probability $\phi$ of report $(\bar{b}, \underline{t})$ by type $\bar{b}, \bar{t}$ is determined as in region 1 and 2 above.

Step 2: The following points have to be checked: 
1. $\phi \leq 1$ yields the condition $\theta \leq \frac{p}{1-p}$.

2. Type $\bar{b}, \bar{t}$ will prefer report $(\underline{b}, \underline{t})$ over truthful reporting because $\omega<\gamma$ in a private firm.

In region $4\left(\theta>\frac{p}{1-p}\right)$ the tax auditor has very low powered audit incentives due to large audit cost or low detection benefits. In this case, auditing will not be profitable even if both $\bar{t}$ types always report $\underline{t}$. Thus, the trivial pure strategy equilibrium emerges.

Consider the publicly listed firm $(\gamma<\omega)$ now. Region $1\left(\theta<\frac{1-p}{p}\right)$ does not differ to private firms and, thus, the proof is identical. The same is true for the trivial equlibrium in region $4\left(\theta>\frac{p}{1-p}\right)$. Therefore we only look at

Region 2: $\frac{1-p}{p}<\theta \leq \frac{p}{1-p}$.

Step 1: The probabilities $\alpha^{f}$ and $\phi$ are obtained as in region 1 (see above).

Step 2: The following conditions have to be checked:

1. $\phi \leq 1$ yields the condition $\theta \leq \frac{p}{1-p}$.

2. Type $\bar{b}, \bar{t}$ prefers truth telling over reporting $(\underline{b}, \underline{t})$ because of $\omega>\gamma$.

3. The tax auditor prefers not to audit report $(\underline{b}, \underline{t})$ because

$$
0.5 p\left(-K_{S}\right)+0.5(1-p)\left(\delta \Delta-K_{S}\right)<0 \Leftrightarrow \theta>\frac{1-p}{p} .
$$

\subsection{Proof of proposition 3}

The proof is very similar to the proof of proposition 2 . We start with the private firm.

Region 1: $\theta<\frac{1-p}{p}$.

Step 1: The probability $\beta^{a}$ will be set such that type $\underline{b}, \bar{t}$ is indifferent between truthful reporting and report $(\underline{b}, \underline{t})$. Solving

$$
\omega \underline{b}-\gamma \bar{t}=\beta^{a}(\omega \underline{b}-\gamma \bar{t}-S)+\left(1-\beta^{a}\right)(\omega \underline{b}-\gamma \underline{t})
$$

yields

$$
\beta^{a}=\frac{\gamma \Delta}{\gamma \Delta+S}
$$

In the equilibrium, type $\bar{b}, \bar{t}$ must be indifferent between report $(\bar{b}, \bar{t})$ and $(\bar{b}, \underline{t})$. Therefore, the probability $\alpha^{a}$ can be determined by

$$
(1-\lambda)(\omega \bar{b}-\gamma \underline{t})+\lambda\left(\alpha^{a}(\omega \bar{b}-\gamma \bar{t}-S)+\left(1-\alpha^{a}\right)(\omega \bar{b}-\gamma \underline{t})\right)=\omega \bar{b}-\gamma \bar{t},
$$


resulting in

$$
\alpha^{a}=\frac{\gamma \Delta}{\lambda(\gamma \Delta+S)} .
$$

Type $\underline{b}, \bar{t}$ taxpayer's reporting strategy is determined by the tax auditor's indifference between audit and non audit upon receiving a report $(\underline{b}, \underline{t})$. We obtain

$$
\frac{(1-p) \eta^{a}}{p+(1-p) \eta^{a}}\left(\delta \Delta-K_{S}\right)+\frac{p}{p+(1-p) \eta^{a}}\left(-K_{S}\right)=0 \Leftrightarrow \eta^{a}=\frac{p}{1-p} \theta .
$$

At last, the tax auditor must be indifferent between non audit and audit after report $(\bar{b}, \underline{t})$ and signal $D$. Using the posterior probability

$$
P(t=\bar{t} \mid \hat{b}=\bar{b}, \hat{t}=\underline{t}, D)=\frac{p \phi^{a} \lambda}{(1-p)(1-\mu)+p \phi^{a} \lambda}
$$

yields

$$
\frac{p \phi^{a} \lambda}{(1-p)(1-\mu)+p \phi^{a} \lambda} \delta \Delta-K_{S}=0 \Leftrightarrow \phi^{a}=\frac{(1-p)(1-\mu)}{p \lambda} \theta .
$$

Step 2: The following equilibrium conditions have to be checked:

1. Type $\bar{b}, \bar{t}$ will not deviate from reporting $(\bar{b}, \bar{t})$ or $(\bar{b}, \underline{t})$ to $(\underline{b}, \underline{t})$, because the auditing probability $\beta^{a}$ determined in (19) implies a payoff $\omega \underline{b}-\gamma \bar{t}$ strictly smaller than $\omega \bar{b}-\gamma \bar{t}$.

2. Condition $0 \leq \alpha^{a} \leq 1$ yields $\lambda \geq \frac{\gamma \Delta}{\gamma \Delta+S}$, which is fulfilled by assumption.

3. Probability $\eta^{a}$ is positive by assumption $\delta \Delta>K_{S}$. $\eta^{a} \leq 1$ can be reformulated to

$$
\theta \leq \frac{1-p}{p} .
$$

4. $0 \leq \phi^{a} \leq 1$ yields

$$
\theta \leq \frac{\lambda}{1-\mu} \frac{p}{1-p} .
$$

Obviously, (26) is stricter than (27) because of $\lambda, \mu$, and $p \geq 1 / 2$.

Region 2: $\frac{1-p}{p}<\theta<\frac{\lambda}{\lambda p+(1-\mu)(1-p)}$.

Step 1: Now, the auditors equilibrium strategies are determined by two indifference conditions concerning the type $\bar{b}, \bar{t}$ - taxpayer's reporting behavior. $\beta^{a}$ can be determined as the solution of

$$
\beta^{a}(\omega \underline{b}-\gamma \bar{t}-S)+\left(1-\beta^{a}\right)(\omega \underline{b}-\gamma \underline{t})=\omega \bar{b}-\gamma \bar{t}
$$


given by

$$
\beta^{a}=\frac{\Delta(\gamma-\omega)}{\gamma \Delta+S}
$$

The second condition (indifference between reports $(\bar{b}, \bar{t})$ and $(\bar{b}, \underline{t})$ ) is identical to the first region. Thus, $\alpha^{a}$ remains unchanged.

The probabilities $\phi^{a}$ and $v^{a}$ are given by the tax auditor's indifference between auditing and not auditing with respect to report $(\underline{b}, \underline{t})$ and $(\bar{b}, \underline{t})$ together with signal $\mathrm{D}$. The first condition is

$$
\left(\delta \Delta-K_{S}\right) \frac{p v^{a}+1-p}{1-p+p\left(1+v^{a}\right)}-K_{S} \frac{p}{1-p+p\left(1+v^{a}\right)}=0
$$

and yields

$$
v^{a}=\theta-\frac{1-p}{p} .
$$

The second condition is as in region 1 , and, thus, $\phi^{a}$ remains unchanged.

Step 2: We have to check the following conditions:

1. $v^{a}+\phi^{a}<1$ yields the upper bound $\theta<\frac{\lambda}{\lambda p+(1-\mu)(1-p)}$. This condition clearly dominates $\phi^{a} \leq 1$.

2. $\beta^{a}>0$ implies $\gamma>\omega$, which holds in a private firm.

Region 3: $\frac{\lambda}{\lambda p+(1-\mu)(1-p)} \leq \theta<\frac{\lambda p}{(1-\mu)(1-p)}$.

Step 1: The equilibrium probability $\alpha^{a}$ can be computed using type $\bar{b}, \bar{t}$ taxpayer's indifference between reporting $(\bar{b}, \underline{t})$ and $(\underline{b}, \underline{t})$. Solving

$$
(1-\lambda)(\omega \bar{b}-\gamma \underline{t})+\lambda\left(\alpha^{a}(\omega \bar{b}-\gamma \bar{t}-S)+\left(1-\alpha^{a}\right)(\omega \bar{b}-\gamma \underline{t})\right)=\omega \underline{b}-\gamma \underline{t}
$$

yields

$$
\alpha^{a}=\frac{\omega \Delta}{\lambda(\gamma \Delta+S)} .
$$

The probability $\phi^{a}$ is again calculated as in region 1 .

Step 2:

1. The upper bound $\theta<\frac{\lambda p}{(1-\mu)(1-p)}$ is determined by $\phi^{a}<1$.

2. In a private firm, $\gamma>\omega$ ensures that a truthful report of type $\bar{b}, \bar{t}$ is dominated by report $(\underline{b}, \underline{t})$. 
3. The auditor prefers not to audit report $(\underline{b}, \underline{t})$, because

$$
\frac{p\left(1-\phi^{a}\right)+1-p}{p+p\left(1-\phi^{a}\right)+1-p}\left(\delta \Delta-K_{S}\right)-\frac{p}{p+p\left(1-\phi^{a}\right)+1-p} K_{S}<0
$$

is equivalent to $\frac{\lambda}{\lambda p+(1-\mu)(1-p)} \leq \theta$.

Consider the publicly listed firm $(\gamma<\omega)$ now. Region $1\left(\theta<\frac{1-p}{p}\right)$ does not differ to private firms and, thus, the proof is identical. The same is true for the trivial equlibrium in region $4\left(\theta>\frac{\lambda p}{(1-\mu)(1-p)}\right)$. Therefore we only look at

Region 2: $\frac{1-p}{p}<\theta \leq \frac{\lambda p}{(1-\mu)(1-p)}$.

Step 1: The probabilities $\alpha^{a}$ and $\phi^{a}$ are obtained as in region 1 (see above).

Step 2: The following conditions have to be checked:

1. $\phi^{a} \leq 1$ yields the condition $\theta \leq \frac{\lambda p}{(1-\mu)(1-p)}$.

2. Type $\bar{b}, \bar{t}$ prefers truth telling over reporting $(\underline{b}, \underline{t})$ because of $\omega>\gamma$.

3. The tax auditor prefers not to audit report $(\underline{b}, \underline{t})$ because

$$
0.5 p\left(-K_{S}\right)+0.5(1-p)\left(\delta \Delta-K_{S}\right)<0 \Leftrightarrow \theta>\frac{1-p}{p} .
$$

\subsection{Proof of proposition 4}

Define $R:=\frac{1-\mu}{\lambda}$ and $A:=\frac{\gamma \Delta}{\gamma \Delta+S}$. The tax revenue and tax audit frequency measures

\begin{tabular}{|c|c|c|c|c|}
\hline$\theta$ & {$\left[0, \frac{1-p}{p}\right)$} & {$\left[\frac{1-p}{p}, 1\right)$} & {$\left[1, \frac{p}{1-p}\right)$} & {$\left[\frac{p}{1-p}, \frac{1}{R} \frac{p}{1-p}\right)$} \\
\hline $\mathrm{TR}^{o}$ & $\frac{\theta}{2}(1-A)$ & & 0.5 & 0.5 \\
\hline $\mathrm{TR}^{f}$ & $\frac{\theta}{2}(1-A)$ & $\frac{1}{2}(1-p)$ & $+\theta(1-A))$ & 0.5 \\
\hline $\mathrm{TR}^{a}$ & $\frac{\theta}{2}((1-p) R+p)(1-A)$ & \multicolumn{3}{|c|}{$\frac{1}{2}(1-p)(1+\theta R(1-A))$} \\
\hline $\mathrm{TA}^{o}$ & $\frac{1+\theta}{2} A$ & & 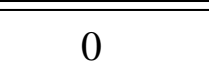 & 0 \\
\hline $\mathrm{TA}^{f}$ & $\frac{1+\theta}{2} A$ & $\frac{1+\theta}{2}$ & $-p) A$ & 0 \\
\hline $\mathrm{TA}^{a}$ & $\frac{1+\theta}{2}((1-p) R+p) A$ & \multicolumn{3}{|c|}{$\frac{1+\theta}{2}(1-p) R A$} \\
\hline
\end{tabular}
are given in the following table:

Table 4: Tax revenue and tax audit probability in publicly listed firms 
The relations given in proposition 4 are easy to see:

- $\theta<\frac{1-p}{p}$ : Note that $(1-p) R+p<1$ because of $R<1$. Then the relations $\mathrm{TR}^{a}<\mathrm{TR}^{f}=\mathrm{TR}^{o}$ and $\mathrm{TA}^{a}<\mathrm{TA}^{f}=\mathrm{TA}^{o}$ are obvious from the table.

- $\frac{1-p}{p} \leq \theta<1: R<1$ implies $\mathrm{TR}^{a}<\mathrm{TR}^{f}$. $\mathrm{TA}^{a}<\mathrm{TA}^{f}<\mathrm{TA}^{o}$ also follows from $R<1$. Reformulating $\mathrm{TR}^{f}=\mathrm{TR}^{o}$ yields a critical value $\theta=\frac{1-p}{p(1-A)}$. Since the critical value may lie in the interior of $\left(\frac{1-p}{p}, 1\right)$, the relation between $\mathrm{TR}^{f}$ and $\mathrm{TR}^{o}$ is indeterminate. The same reasoning applies for $\mathrm{TR}^{a}=\mathrm{TR}^{o}$ implying a critical $\theta=\frac{1-p}{(1-(1-p) R)(1-A)}$ that may also be in the interior of $\left(\frac{1-p}{p}, 1\right)$.

- $1 \leq \theta<\frac{p}{1-p}$ : Again, $R<1$ implies $\mathrm{TR}^{a}<\mathrm{TR}^{f}<\mathrm{TR}^{o}$ and $\mathrm{TA}^{o}<\mathrm{TA}^{a}<\mathrm{TA}^{f}$.

- $\frac{p}{1-p} \leq \theta<\frac{\lambda}{1-\mu} \frac{p}{1-p}$ : It is easy to show that $\frac{1}{2}(1-p)(1+\theta R(1-A))<\frac{1}{2}$. Therefore, $\mathrm{TR}^{a}<\mathrm{TR}^{f}=\mathrm{TR}^{o}$. Obviously, $\frac{1+\theta}{2}(1-p) R A>0$. Thus, $\mathrm{TA}^{o}=\mathrm{TA}^{f}<$ $\mathrm{TA}^{a}$.

\subsection{Proof of proposition 5}

First, note that tax revenue and the audit frequency measures for $\theta<\frac{1-p}{p}$ are the same as in proposition 4. We define $R:=\frac{1-\mu}{\lambda}, A:=\frac{\gamma \Delta}{\gamma \Delta+S}$, and $B:=\frac{\omega \Delta}{\gamma \Delta+S}$. Furthermore, $\bar{\theta}_{1}=\frac{1-p}{p}, \bar{\theta}_{2}=\frac{\lambda p}{\lambda p+(1-\mu)(1-p)}$ and $\bar{\theta}_{3}=\frac{\lambda p}{(1-\mu)(1-p)}$. Then the tax revenue and audit frequency measures for $\theta>\bar{\theta}_{1}$ are given as in the following table:

\begin{tabular}{l|c|c|c|c}
\hline$\theta$ & {$\left[\bar{\theta}_{1}, 1\right)$} & {$\left[1, \min \left\{\bar{\theta}_{2}, \frac{p}{1-p}\right\}\right)$} & {$\left[\min \left\{\bar{\theta}_{2}, \frac{p}{1-p}\right\}, \frac{p}{1-p}\right)$} & {$\left[\frac{p}{1-p}, \bar{\theta}_{3}\right)$} \\
\hline \hline $\mathrm{TR}^{o}$ & $\frac{\theta}{2}(1-A)$ & 0.5 & 0.5 & 0.5 \\
\hline $\mathrm{TR}^{f}$ & $\frac{\theta}{2}((1-A)+p B)$ & $0.5(1-B(1-p) \theta)$ & 0.5 \\
\hline $\mathrm{TR}^{a}$ & $\frac{\theta}{2}((1-A)((1-p) R+p)+p B)$ & $0.5(1-B(1-p) R \theta)$ \\
\hline \hline $\mathrm{TA}^{o}$ & $\frac{1+\theta}{2} A$ & 0 & 0 & 0 \\
\hline $\mathrm{TA}^{f}$ & $\frac{1+\theta}{2}(A-p B)$ & \multicolumn{2}{|c|}{$\frac{1+\theta}{2}(1-p) B$} & 0 \\
\hline $\mathrm{TA}^{a}$ & $\frac{1+\theta}{2}[((1-p) R+p) A-p B]$ & $\frac{1+\theta}{2}(1-p) R B$ & \\
\hline
\end{tabular}

Table 5: Tax revenue and tax audit probability in private firms.

Most of the statements in proposition 5 can be seen directly in the table: 
- $\frac{1-p}{p}=\bar{\theta}_{1}<\theta \leq 1: \mathrm{TR}^{a}<\mathrm{TR}^{f}$ follows from $(1-p) R+p<1 . \mathrm{TR}^{f}>\mathrm{TR}^{o}$ and $\mathrm{TA}^{a}<\mathrm{TA}^{f}<\mathrm{TA}^{0}$ are obvious from the table. The relation $\mathrm{TR}^{a} \gtreqless \mathrm{TR}^{o}$ is valid because $\mathrm{TR}^{a}<\mathrm{TR}^{o}$ for $R \rightarrow 0$ and $B$ sufficiently low and $\mathrm{TR}^{a}>\mathrm{TR}^{o}$ for $R$ sufficiently large.

- $1 \leq \theta<\min \left\{\frac{p}{1-p} ; \frac{\lambda}{\lambda p+(1-\mu)(1-p)}\right\}: \mathrm{TR}^{o}>\mathrm{TR}^{f}, \mathrm{TR}^{o}>\mathrm{TR}^{a}, \mathrm{TA}^{o}<\mathrm{TA}^{f}$ and $\mathrm{TA}^{o}<\mathrm{TA}^{a}$ are obvious from the table. $\mathrm{TA}^{a}>\mathrm{TA}^{f}$ is equivalent to

$$
\frac{B}{A}<(1-p) R+p
$$

This condition may be fulfilled for feasible parameters in our model. Reformulating $\mathrm{TA}^{a}<\mathrm{TA}^{f}$ yields

$$
\theta<\frac{1}{(1-A)((1-p) R+p)+B}:=\hat{\theta} .
$$

A sufficient condition for $\mathrm{TA}^{a}<\mathrm{TA}^{f}$ for all $\theta \in\left[1, \min \left\{\bar{\theta}_{2}, \frac{p}{1-p}\right\}\right)$ is $\hat{\theta}>\bar{\theta}_{2}=$ $\frac{1}{(1-p) R+p)}$. Rearranging this claim yields

$$
\frac{B}{A}<(1-p) R+p .
$$

Thus, the necessary and sufficient condition for $\mathrm{TA}^{a}>\mathrm{TA}^{f}$ implies $\mathrm{TR}^{a}<$ $\mathrm{TA}^{f}$ for all $\theta \in\left[1, \min \left\{\bar{\theta}_{2}, \frac{p}{1-p}\right\}\right)$.

- $\min \left\{\frac{p}{1-p} ; \frac{\lambda}{\lambda p+(1-\mu)(1-p)}\right\} \leq \theta<\frac{p}{1-p}: R<1$ implies the relations $\mathrm{TR}^{f}<\mathrm{TR}^{a}<$ $\mathrm{TR}^{o}$ and $\mathrm{TA}^{o}<\mathrm{TA}^{a}<\mathrm{TA}^{f}$.

- $\frac{p}{1-p} \leq \theta<\frac{\lambda}{1-\mu} \frac{p}{1-p}: \mathrm{TR}^{a}<\mathrm{TR}^{f}=\mathrm{TR}^{o}$ and $\mathrm{TA}^{a}>\mathrm{TA}^{f}=\mathrm{TA}^{o}$ is obvious from the table.

\subsection{Derivation of tables 1 and 2}

The following tables can directly be derived from tables 4 and 5. $A, B$ and $R$ are defined as above. The first table contains the partial derivatives for publicly listed firms. Using $\frac{\partial A}{\partial \gamma}:=A_{\gamma}=\frac{S \Delta}{(\gamma \Delta+S)^{2}}>0$, the signs in table 1 are obvious from the table below. 


\begin{tabular}{c|cc|cc|c}
\hline$\theta$ & $\frac{\partial \mathrm{TR}^{f}}{\partial p}$ & $\frac{\partial \mathrm{TR}^{a}}{\partial p}$ & $\frac{\partial \mathrm{TR}^{f}}{\partial \gamma}$ & $\frac{\partial \mathrm{TR}^{a}}{\partial \gamma}$ & $\frac{\partial \mathrm{TR}^{a}}{\partial R}$ \\
\hline \hline$\left[0, \frac{1-p}{p}\right)$ & 0 & $\frac{\theta(1-A)(1-R)}{2}$ & $-A \gamma \frac{\theta}{2}$ & $-A \gamma \frac{(1-p) R \theta}{2}$ & $\frac{\theta(1-A)(1-p)}{2}$ \\
{$\left[\frac{1-p}{p}, 1\right)$} & $\frac{-1-\theta(1-A)}{2}$ & $\frac{-1-R \theta(1-A)}{2}$ & $-A \gamma \frac{\theta(1-p)}{2}$ & $-"-$ & $-"-$ \\
{$\left[1, \frac{p}{1-p}\right)$} & $-"-$ & $-"-$ & $-"-$ & $-"-$ & $-"-$ \\
{$\left[\frac{p}{1-p}, \frac{1}{R} \frac{p}{1-p}\right)$} & $-"-$ & 0 & $-"-$ & 0 & $-"-$ \\
\hline
\end{tabular}

The next two tables contain the partial derivatives for private firms. Note that $\frac{\partial B}{\partial \gamma}:=$ $B_{\gamma}=-\frac{\omega \Delta^{2}}{(\gamma \Delta+S)^{2}}<0$ and $\frac{\partial B}{\partial \omega}:=B_{\omega}=\frac{\Delta}{\gamma \Delta+S}>0$ imply the signs stated in table 2.

\begin{tabular}{c|cc|cc}
\hline$\theta$ & $\frac{\partial \mathrm{TR}^{f}}{\partial p}$ & $\frac{\partial \mathrm{TR}^{a}}{\partial p}$ & $\frac{\partial \mathrm{TR}^{f}}{\partial \gamma}$ & $\frac{\partial \mathrm{TR}^{a}}{\partial \gamma}$ \\
\hline \hline$\left[0, \frac{1-p}{p}\right)$ & 0 & $\frac{\theta(1-A)(1-R)}{2}$ & $-A_{\gamma} \frac{\theta}{2}$ & $-A_{\gamma} \frac{(1-p) R \theta}{2}$ \\
{$\left[\frac{1-p}{p}, 1\right)$} & $\frac{\theta B}{2}$ & $\frac{\theta(B+(1-A)(1-R))}{2}$ & $\frac{\theta}{2}\left(p B_{\gamma}-A_{\gamma}\right)$ & $\frac{\theta}{2}\left(p B_{\gamma}-A_{\gamma}((1-p) R+p)\right)$ \\
{$\left[1, \min \left\{\bar{\theta}_{2}, \frac{p}{1-p}\right\}\right)$} & $-"-$ & $-"-$ & $-\frac{\theta}{2}(1-p) B_{\gamma}$ & $-"-$ \\
{$\left[\min \left\{\bar{\theta}_{2}, \frac{p}{1-p}\right\}, \frac{p}{1-p}\right)$} & $-"-$ & $\frac{\theta B R}{2}$ & $-"-$ & $-\frac{\theta}{2}(1-p) R B_{\gamma}$ \\
{$\left[\frac{p}{1-p}, \theta_{3}\right)$} & 0 & $-"-$ & 0 & $-"-$ \\
\hline
\end{tabular}

\begin{tabular}{c|cc|c}
\hline$\theta$ & $\frac{\partial \mathrm{TR}^{f}}{\partial \omega}$ & $\frac{\partial \mathrm{TR}^{a}}{\partial \omega}$ & $\frac{\partial \mathrm{TR}^{a}}{\partial R}$ \\
\hline \hline$\left[0, \frac{1-p}{p}\right)$ & 0 & 0 & $\frac{\theta(1-A)(1-p)}{2}$ \\
{$\left[\frac{1-p}{p}, 1\right)$} & $\frac{\theta}{2} p B_{\omega}$ & $\frac{\theta}{2} p B_{\omega}$ & $-"-$ \\
{$\left[1, \min \left\{\bar{\theta}_{2}, \frac{p}{1-p}\right\}\right)$} & $-\frac{\theta}{2}(1-p) B_{\omega}$ & $-"-$ & $-"-$ \\
{$\left[\min \left\{\bar{\theta}_{2}, \frac{p}{1-p}\right\}, \frac{p}{1-p}\right)$} & $-"-$ & $-\frac{\theta}{2}(1-p) R B_{\omega}$ & $-\frac{\theta B(1-p)}{2}$ \\
{$\left[\frac{p}{1-p}, \theta_{3}\right)$} & 0 & $-"-$ & $-"-$ \\
\hline
\end{tabular}

